\title{
Joint earthquake source inversions using seismo-geodesy and 3-D earth models
}

\author{
J. Weston, ${ }^{1, *}$ A.M.G. Ferreira ${ }^{1,2, \dagger}$ and G. J. Funning ${ }^{3}$ \\ ${ }^{1}$ School of Environmental Sciences, University of East Anglia, Norwich, UK.E-mail: j.weston@uea.ac.uk \\ ${ }^{2}$ ICIST, Instituto Superior Tecnico, Technical University of Lisbon, Lisbon, Portugal \\ ${ }^{3}$ Department of Earth Sciences, University of California, Riverside, CA, USA
}

Accepted 2014 March 20. Received 2014 March 17; in original form 2013 August 23

\begin{abstract}
S UMMAR Y
A joint earthquake source inversion technique is presented that uses InSAR and long-period teleseismic data, and, for the first time, takes 3-D Earth structure into account when modelling seismic surface and body waves. Ten average source parameters (Moment, latitude, longitude, depth, strike, dip, rake, length, width and slip) are estimated; hence, the technique is potentially useful for rapid source inversions of moderate magnitude earthquakes using multiple data sets. Unwrapped interferograms and long-period seismic data are jointly inverted for the location, fault geometry and seismic moment, using a hybrid downhill Powell-Monte Carlo algorithm. While the InSAR data are modelled assuming a rectangular dislocation in a homogeneous halfspace, seismic data are modelled using the spectral element method for a 3-D earth model. The effect of noise and lateral heterogeneity on the inversions is investigated by carrying out realistic synthetic tests for various earthquakes with different faulting mechanisms and magnitude $\left(M_{\mathrm{W}} 6.0-6.6\right)$. Synthetic tests highlight the improvement in the constraint of fault geometry (strike, dip and rake) and moment when InSAR and seismic data are combined. Tests comparing the effect of using a 1-D or 3-D earth model show that long-period surface waves are more sensitive than long-period body waves to the change in earth model. Incorrect source parameters, particularly incorrect fault dip angles, can compensate for systematic errors in the assumed Earth structure, leading to an acceptable data fit despite large discrepancies in source parameters. Three real earthquakes are also investigated: Eureka Valley, California (1993 May 17, $M_{\mathrm{w}} 6.0$ ), Aiquile, Bolivia (1998 February 22, $M_{\mathrm{w}} 6.6$ ) and Zarand, Iran (2005 May 22, $M_{\mathrm{w}} 6.5$ ). These events are located in different tectonic environments and show large discrepancies between InSAR and seismically determined source models. Despite the 40$50 \mathrm{~km}$ discrepancies in location between previous geodetic and seismic estimates for the Eureka Valley and Aiquile earthquakes, the seismic data are found to be compatible with the InSAR location. A $30^{\circ}$ difference in strike between InSAR and seismic-derived source models is also resolved when taking 3-D Earth structure into account in the analysis of the Eureka Valley earthquake. The combination of both InSAR and seismic data further constrains the dip for the Zarand earthquake, and in all cases the seismic moment is more robustly constrained in the joint inversions than in the individual data set inversions. Unmodelled lateral heterogeneities in Earth and the models could partly explain some of the observed source parameter discrepancies related to the seismic data.
\end{abstract}

Key words: Seismic cycle; Earthquake source observations; Computational seismology.

\footnotetext{
*Now at: School of Earth and Space Exploration, Arizona State University, Tempe, AZ, USA.

${ }^{\dagger}$ Now at: Department of Earth Sciences, University College London, London, UK.
}

\section{INTRODUCTION}

Recent earthquakes such as Haiti $\left(M_{\mathrm{w}} 7.0,2010\right.$ January 10$)$ and Tohoku, Japan, ( $M_{\mathrm{w}}$ 9.1, 2011 March 11) have highlighted the importance of accurate and robust source models. Initial estimates within minutes of an earthquake can be used to model the extent and severity of the resulting damage, such as with the United States 
Geological Survey's (USGS) Prompt Assessment of Global Earthquakes for Response (PAGER) system, providing vital information for an emergency response. On a longer timescale, robust source models are needed for Coloumb stress change calculations (e.g. King et al. 1994; Astiz et al. 2000; Enescu et al. 2012), and seismotectonic studies (e.g. Jackson \& McKenzie 1984; Dewey \& Lamb 1992; Ambraseys \& Jackson 1998), both of which are useful for understanding regional seismic hazard.

Traditionally, routine earthquake source parameter determinations have been based on seismic data, with numerous global and regional catalogues available, including the National Earthquake Information Centre (NEIC) Preliminary Determination of the Epicentre (PDE) catalogue (USGS, 2013), the Global Centroid Moment Tensor Catalogue (GCMT, Dziewonski et al. 1981; Ekström et al. 2012), SCARDEC (Vallée et al. 2011), and the National Research Institute for Earth Science and Disaster Prevention (NIED) Catalogue for Japan (Kubo et al. 2002; Okada et al. 2004).

The development and expansion of space geodetic techniques such as global positioning system (GPS) and Interferometric Synthetic Aperture Radar (InSAR) provided a means independent of seismic data for the determination of earthquake source models. In particular, the fine spatial resolution of space-based geodesy allows the accurate location of events, which is complementary to the high temporal resolution of seismic data that enables a comprehensive characterization of the rupture. Moreover, often source models derived from seismic and geodetic data have complementary source parameter trade-offs. For example, models derived from InSAR data are often affected by a rake-moment trade-off (e.g. Berberian et al. 2001; Funning 2005; Schmidt \& Bürgmann 2006). On the other hand, it has been widely documented that source inversions of shallow earthquakes based on long-period seismic data lead to a strong moment-dip trade-off (e.g. Kanamori \& Given 1981; Funning 2005; Ferreira \& Woodhouse 2006; Tsai et al. 2011). Consequently, various 'seismo-geodetic' inversion techniques have been developed using combinations of InSAR, GPS, teleseismic, regional and strong motion measurements.

Initial approaches took a least-squares approach by fixing the fault geometry and solving the linear problem of the slip distribution (Wald \& Heaton 1994). Later studies incorporated the temporal resolution of the seismic data to determine rupture velocity and rise time, as well as the slip amplitude and direction, assuming homogeneous (e.g. Delouis et al. 2002) or layered elastic halfspaces (e.g. Ji et al. 2002). To solve the nonlinear problem of fault geometry, search methods, such as the neighbourhood algorithm (Sambridge 1999) or the Powell algorithm (Powell 1964), have been used to determine the optimal solution (e.g. Lohman et al. 2002; Wright et al. 2003; Funning 2005).

The majority of previous joint inversion studies assume a 1-D Earth structure when modelling the various types of seismic data: teleseismic body waves (e.g. Ji et al. 2002), long-period surface waves (Funning 2005), local (e.g. Kaverina et al. 2002), regional (e.g. Lohman et al. 2002) or strong motion data (e.g. Hernandez et al. 1999). The study by Wald \& Graves (2001) was one of the first to consider the effects of 3-D Earth structure when calculating the Green's functions for strong motion data, by forward modelling the strain on a predefined fault structure using a set body force applied at each strong motion station (Graves \& Wald 2001). Previous comparisons of seismic and geodetic source models reported in source catalogues have highlighted the influence of the assumed Earth structure when modelling the seismic data (e.g. Ferreira et al. 2011; Weston et al. 2011, 2012). Errors in the Earth model can lead to uncertainties in the source parameters, including an overestima- tion of the seismic moment (e.g. Ferreira \& Woodhouse 2006), incorrect non-double-couple component values (e.g. Covellone \& Savage 2012) and also shifts in location (e.g. Hjörleifsdóttir \& Ekström 2009; Syracuse \& Abers 2009).

Despite the various existing techniques, there is not a catalogue which routinely reports seismo-geodetic source models calculated using a homogeneous approach. Although there are a couple of archives which compile source models reported in the literature, such as SRCMOD (Mai 2004) and ICMT (Weston et al. 2011, 2012), new catalogues based on the systematic application of seismogeodetic techniques would be highly beneficial. In this study, we present a joint earthquake source inversion technique that could be routinely applied and that takes into account lateral heterogeneities in the Earth when modelling the seismic data. Given the high spatial accuracy of InSAR data for locating events, the locations obtained from InSAR-only inversions are used to calculate excitation kernels for long-period teleseismic surface and body waves, which are jointly inverted with InSAR data to determine ten earthquake source parameters. We perform synthetic tests based on real events to investigate the influence of data noise and 3-D Earth structure in the inversions, and to highlight the benefits of combining the two data sets. Three real case studies from different tectonic settings are also investigated to explore the benefits of the joint inversion approach. Specifically, we investigate events for which large discrepancies between InSAR-derived and GCMT source parameters have been reported, including significant disagreements in location for two of the earthquakes studied here: Eureka Valley, California, 1993 May 17, $M_{\mathrm{w}} 6.0$ and Aiquile, Bolivia, 1998 February 22. The third earthquake, Zarand, 2005 May 22, $M_{\mathrm{w}} 6.5$, is selected due to the $20^{\circ}$ discrepancy in dip between the GCMT solution and that of Talebian et al. (2006). For the events in central Iran and in the central Andes in Bolivia, robust source models are particularly important as there is still much debate surrounding the tectonic regime and seismic hazard in these regions.

\section{METHOD}

The technique presented below combines the strengths of both InSAR and long-period seismic data to characterize the earthquake source. Assumptions regarding the earthquake source and the weighting approach are discussed, as well as the method used to incorporate the effects of 3-D Earth structure when modelling the seismic data. This is followed by a description of the optimization scheme used to solve the non-linear problem to determine ten source parameters - seismic moment, centroid spatial location (latitude, longitude and depth), fault's strike, dip and rake, average slip, length and width.

\subsection{Characterization of the earthquake source}

The InSAR data are modelled using an analytical elastic dislocation model code (Okada 1985), assuming uniform slip on a finite fault, which is described by the 10 source parameters introduced above. The corresponding source assumption for the seismic data involves treating the earthquake as a point source, including the six independent components of the moment tensor:

$\mathbf{f}=\left[\begin{array}{llllll}M_{r r} & M_{\theta \theta} & M_{\phi \phi} & M_{r \theta} & M_{r \phi} & M_{\theta \phi}\end{array}\right]$.

Following the conventions of Aki \& Richards (2002) these six components of the moment tensor can be expressed in terms of strike, dip, rake and seismic moment for a pure double-couple source. 
Assuming a fixed centroid location, the $n$th component of a seismogram $s_{n}$ can be represented by the following linear relationship (e.g. Gilbert \& Dziewonski 1975):

$s_{n}(x, t)=\sum_{i=1}^{6} f_{i} K_{i}$,

where $\mathbf{K}$ - the excitation kernels - are the partial derivatives of the seismograms with respect to the moment tensor components:

$K_{i}=\frac{\partial s_{n}}{\partial f_{i}}$.

Most joint inversion approaches assume a 1-D Earth model when calculating these excitation kernels, but here the effects of 3-D Earth structure are taken into account when modelling the seismic data.

\subsection{Synthetic seismograms, kernels and earth models used}

Synthetic seismograms and partial derivatives with respect to the seismic moment tensor are calculated using the spectral element wave propagation package SPECFEM3D Globe (Komatitsch \& Tromp 1999). This technique takes into account 3-D Earth structure, as well as the effects of gravity, Earth's rotation, attenuation, topography and ocean loading on seismic waveforms. A variety of Earth models can be used; in this study the shear wave mantle model S40RTS (Ritsema et al. 2011) is used in combination with the crustal model CRUST 2.0 (Bassin et al. 2000), which are readily available and widely used by the seismology community. We calculate 90-min-long theoretical seismograms for 129 stations and accurate down to a period of $15 \mathrm{~s}$ (Komatitsch \& Tromp 2010), with each run taking approximately six hours using 864 processors on the UK's supercomputer HECToR. Since the earthquakes studied have moderate magnitudes, we model the source time function as a Dirac delta function. This assumption can be used because the source dimension $(<100 \mathrm{~km})$ and duration $(<30 \mathrm{~s})$ of the earthquakes studied will typically be much less than the wavelength and period of the seismic data used. In addition, given the high spatial accuracy of InSAR data and the limitations in earthquake locations obtained from long-period seismic data (e.g. Ferreira et al. 2011), we use the centroid latitude and longitude obtained from inversions of InSAR data alone. The kernels for all the events in this study are calculated at a fixed depth of $12 \mathrm{~km}$, as for very shallow sources the surface wave kernels associated with $M_{r \theta}$ and $M_{r \phi}$ are small, which can lead to instabilities in the inversions (Dziewonski et al. 1981). We also fix the centroid time to that reported in the GCMT, thus the seismic inversion is a linear problem and, for each earthquake, the six moment tensor excitation kernels only need to be calculated once. The seismic kernels are unlikely to vary significantly over the spatial domain searched in the InSAR part of the inversion, which is smaller (typically $<40 \mathrm{~km}$ ) than the spatial horizontal resolutions of the crust $(\sim 200 \mathrm{~km})$ and mantle $(\sim 500 \mathrm{~km})$ in the earth model used.

An example of excitation kernels calculated for a shallow earthquake $(h=12 \mathrm{~km}$ ) located in Northern California for station TLY in Russia (epicentral distance $84.0^{\circ}$, azimuth $336.0^{\circ}$ ) is shown in Fig. 1. This location was chosen as there are large amounts of InSAR data available for California and the station was selected as a good example which highlights the differences between kernels calculated using 1-D and 3-D Earth models. Threecomponent body and surface wave kernels for the 3-D Earth model S40RTS combined with CRUST2.0 (hereafter referred to as 3-D kernels) are compared with normal mode summation calculations (Gilbert 1976) for the spherically symmetric earth model PREM
(Dziewonski \& Anderson 1981), hereafter referred to as 1-D kernels. The long-period surface wave kernels associated with $M_{r \theta}$ and $M_{r \phi}$ have low amplitudes as expected because the ground motions are relatively insensitive to these components; hence, these components are less well constrained in source inversions for shallow events (e.g. Dziewonski et al. 1981). In addition, Fig. 1 shows that there are substantial differences between 1-D and 3-D kernels for both body and surface wave kernels.

The InSAR data are modelled assuming a homogeneous halfspace (Okada 1985) where, $\mu=3 \times 10^{10} \mathrm{~Pa}$ and $\lambda=3 \times 10^{10}$ $\mathrm{Pa}$. Previous comparisons between the effects of a layered or homogeneous half-space have shown that a homogeneous half-space can lead to systematically shallower depths, with a bias of up to 30 per cent (e.g. Savage 1987; Marshall et al. 1991; Lohman et al. 2002; Hearn \& Bürgmann 2005). This effect is mechanism dependent as the use of a layered half-space amplifies the horizontal displacements, which is mainly a concern for strike-slip events (Hearn \& Bürgmann 2005). Overall the use of homogeneous half-space elastic models has been found to be acceptable to model geodetic data (e.g. Wald \& Graves 2001), and for our technique it is adequate as a first approximation.

\subsection{Misfit function and weighting}

To quantify the fit between the forward-modelled synthetics and the data, an $\mathrm{L}_{2}$-norm misfit function is used involving differences between the observed seismograms $\mathbf{d}_{\mathrm{S}}$ and the theoretical seismograms $\mathbf{t}_{\mathrm{S}}$, and between observed and theoretical downsampled InSAR displacements ( $\mathbf{d}_{\mathrm{I}}$ and $\mathbf{t}_{\mathrm{I}}$, respectively):

$m^{2}=\alpha_{\mathrm{S}} \frac{\left(t_{\mathrm{S}}-d_{\mathrm{S}}\right)^{T}\left(t_{\mathrm{S}}-d_{\mathrm{S}}\right)}{d_{\mathrm{S}}^{T} d_{\mathrm{S}}}+\alpha_{\mathrm{I}} \frac{\left(t_{\mathrm{I}}-d_{\mathrm{I}}\right)^{T}\left(t_{\mathrm{I}}-d_{\mathrm{I}}\right)}{d_{\mathrm{I}}^{T} d_{\mathrm{I}}}$,

where $\alpha_{\mathrm{S}}$ and $\alpha_{\mathrm{I}}$ are the weights given to the seismic and InSAR data in the inversions, respectively. The mean misfit values obtained from separate inversions of InSAR and seismic data are used as guides to determine the weights $\alpha_{\mathrm{S}}$ and $\alpha_{\mathrm{I}}$. If there are multiple seismic or geodetic data sets, these are also inverted separately to ensure all features of each data set are properly taken into account. This weighting approach is relatively simple and is reliant on the assumption that the data sets are best fit when treating the earthquake as a simple point source or uniform slip finite fault. For cases where this assumption is perhaps not realistic enough, such as for the 2005 Zarand earthquake studied in Section 7, the weighting approach is slightly modified. A weight-search approach is used, whereby multiple joint inversions are carried out and after every run the misfit for each data set is compared to that from the separate inversion. This is used as a guide for adjusting the weights in the various inversions until the degradation in misfit in the joint inversions compared to the separate inversions is of similar magnitude for all data sets. For further details on the weights used for the events in this study please see Fig. S1.

\subsection{Optimization scheme}

Fig. 2 shows a flowchart illustrating our joint source inversion algorithm. The technique is based on an approach originally used for geodetic data (Clarke et al. 1997; Wright et al. 1999), which has been modified to include seismic data. A downhill Powell scheme with multiple Monte Carlo starts is used to determine optimal earthquake point source model solutions. The Powell algorithm is a non-linear optimization algorithm (Powell 1964), which covaries 
(a) LPS Z

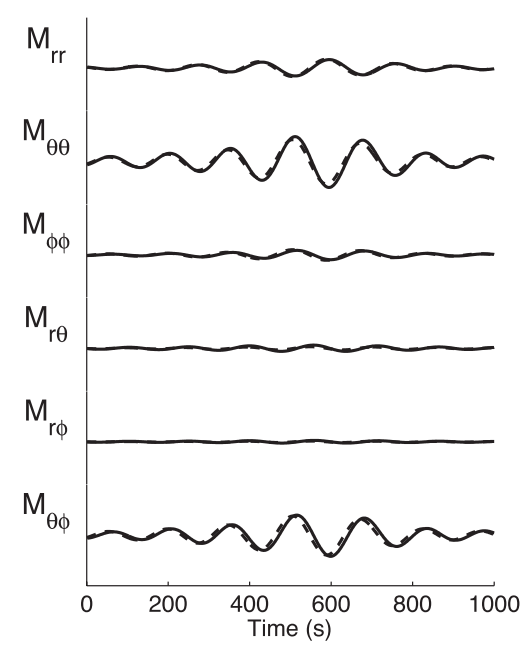

(d) LPB Z

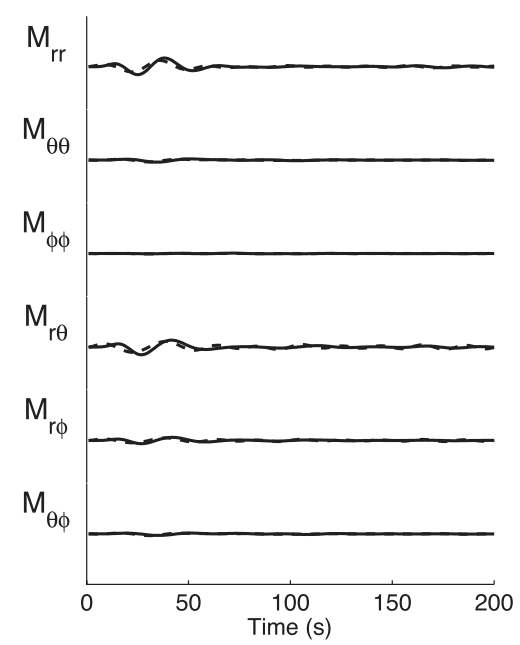

(b) LPS T

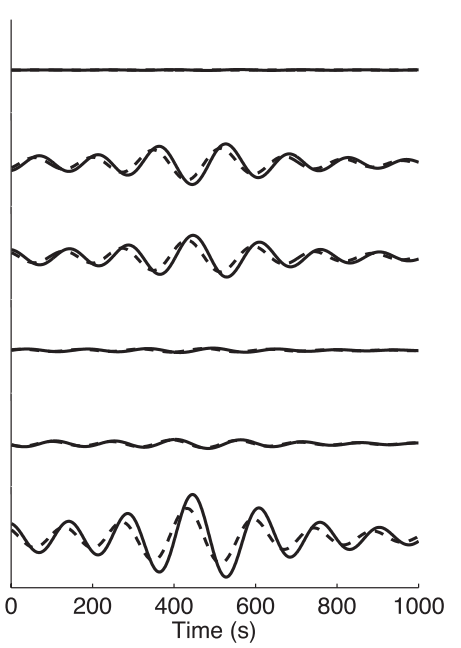

(e) LPB T

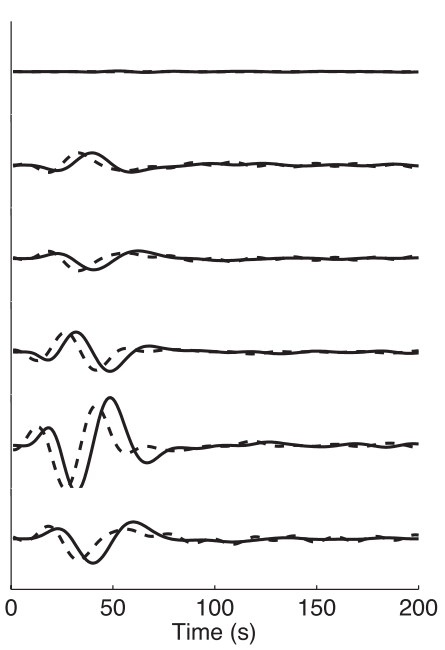

(c) LPS L

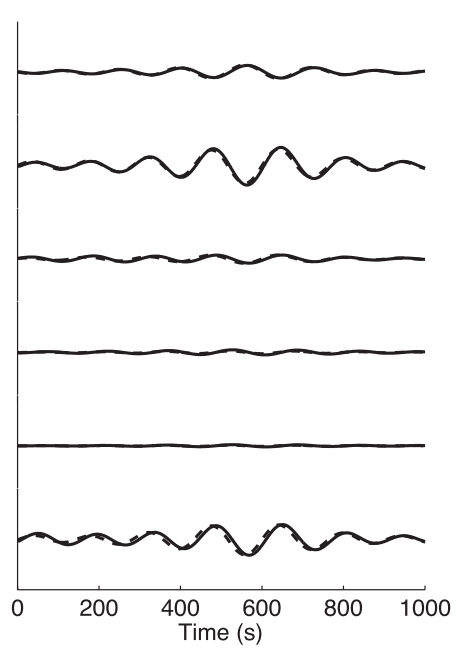

(f) LPB L

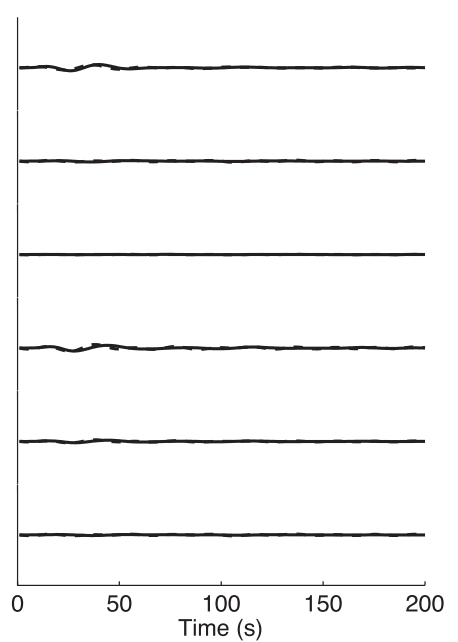

Figure 1. Three component excitation kernels calculated using S40RTS combined with CRUST2.0 (solid black line) in comparison with kernels calculated using PREM (dashed line) for a source located at latitude $37.092^{\circ}$, longitude $-117.930^{\circ}$ and $12 \mathrm{~km}$ depth for station TLY (Russia). (a-c) Kernels for long-period surface waves (LPS) in vertical (Z), transverse (T) and longitudinal (L) components, respectively. (d-f) Kernels for long-period body waves (LPB) in the same three components.

multiple parameters to search the parameter space for the combination of parameters that provides the best fit to the data. The algorithm manipulates individual parameters/groups of parameters until a local minimum in misfit is found, and then searches in an orthogonal direction, and so on, until no further improvement in the data fit can be achieved. In practice theoretical seismograms and line-of-sight (LOS) displacements are repeatedly calculated and compared with the data to determine the misfit (defined in eq. 4). This is used as a penalty function, which guides the algorithm until a model leading to a minimum of the misfit function is found. Often, the resulting source model represents a local minimum which depends on the initial parameter estimates specified at the start of the inversion. Therefore to determine the source parameters corresponding to the global minimum misfit, the algorithm is restarted multiple times using different starting model parameters selected randomly within specified bounds. The inversion finishes when either five of the lowest misfits are within $1 \times 10^{-5}$ of each other or 200 restarts are completed, whichever is achieved first.

\section{DATA}

\subsection{Teleseimic waveform data}

Three-component seismic data recorded at stations from the GSN, GEOFON and GEOSCOPE networks are downloaded from Incorporated Research Institutions for Seismology (IRIS) for events of interest. The horizontal components are rotated into longitudinal and transverse components and all three components are deconvolved to remove the instrument response. Two time windows are used: (i) a window including long-period surface waves with a dominant wave period of $T \sim 150 \mathrm{~s}$ (hereafter referred to as LPS) obtained through convolution with the response of an SRO instrument and filtering with cosine high and low pass filters, in the period range of $T \sim 135-1000 \mathrm{~s}$; (ii) a window centered on $T \sim 30 \mathrm{~s}$ body waves (hereafter referred to as LPB), which are band-pass filtered using Butterworth filters in the period range $T \sim 25-100 \mathrm{~s}$. 


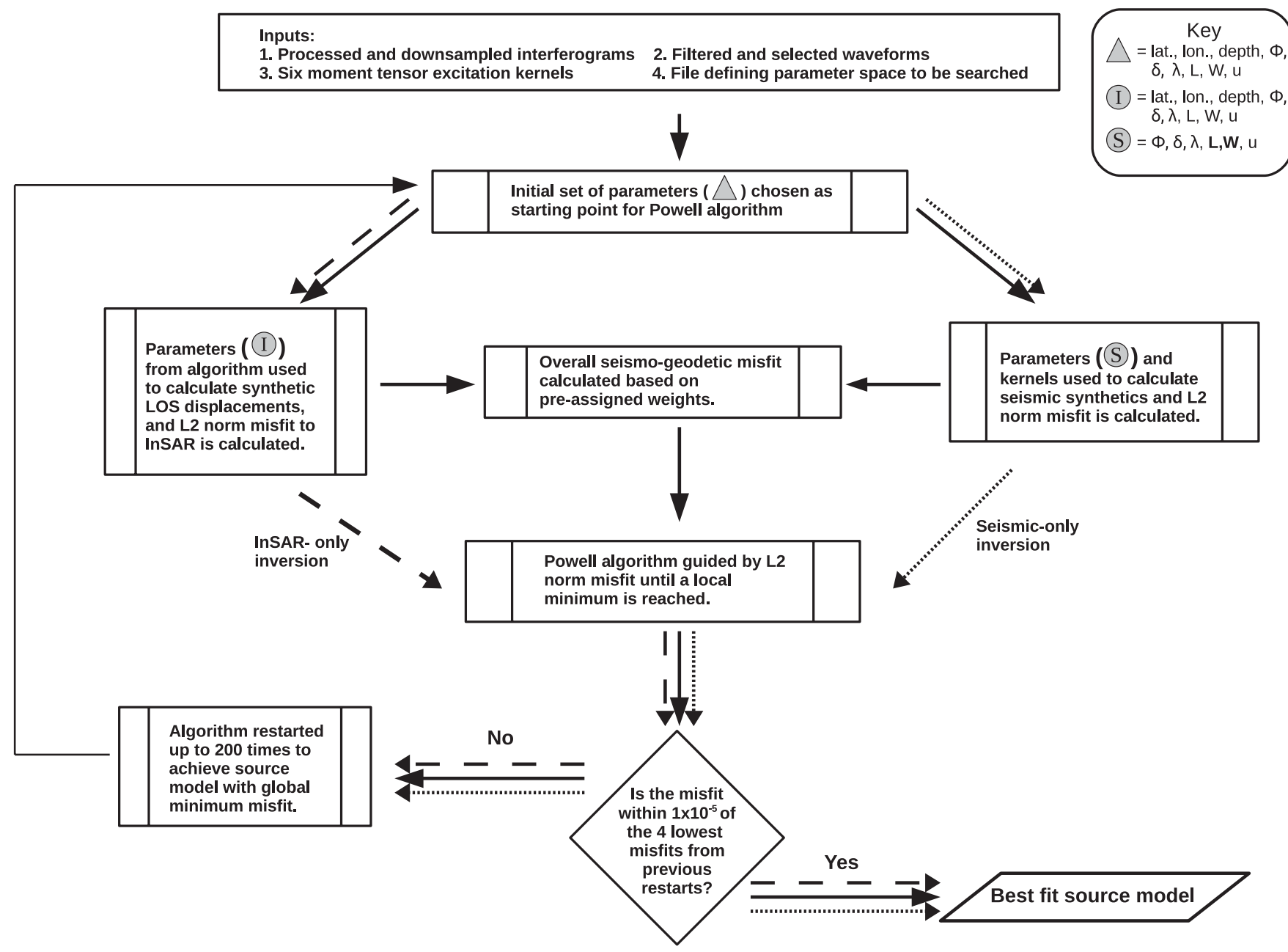

Figure 2. Flowchart illustrating the joint inversion approach. Solid arrows show the pathway taken in the joint inversion, dashed and dotted lines show pathways for separate InSAR and seismic inversions, respectively. The parameters solved for in the separate and joint inversions are represented by the symbols described in the key where lat., lon., and depth refer to the centroid latitude, longitude, and depth, respectively, $\Phi=$ strike, $\delta=\operatorname{dip}, \lambda=\operatorname{rake}, \mathrm{L}=$ along-strike length, $\mathrm{W}=$ downdip width, and $\mathrm{u}=$ slip. Parameters in bold were fixed during the inversion. Note the inversion will finish if either five of the lowest misfits within $1 \times 10^{-5}$ of each other are obtained or if 200 restarts are completed, whichever is achieved first.

In order to minimize near-source effects, caustics and multiple orbit overlapping wave trains, we consider stations with epicentral distances in the range $40^{\circ}-140^{\circ}$ for LPS and $30^{\circ}-90^{\circ}$ for LPB. Noisy components are identified via the visual examination of the waveforms, thus not all three components for some stations may be used and some stations are completely removed, consequently the total number of waveforms can vary between surface and body waves. In order to ensure an even azimuthal distribution of stations, whenever data from multiple stations are available in a $5^{\circ}$ azimuthal interval, we only use the station which has the best signal-to-noise ratio.

\subsection{InSAR data}

Interferograms used in this study are produced using SAR images from ENVISAT, ERS-1 and ERS-2 satellites. Whenever possible, data from both ascending and descending tracks are used. Image pairs with short temporal separations and favorable perpendicular baselines are selected (see Table S1 for details) to minimize decorrelation and topographic artifacts in the processed data. The images are processed using Repeat Orbit Interferometry Package
(ROI_PAC, Rosen et al. 2004), where the interferograms are filtered using a power spectrum filter (Goldstein \& Werner 1998) and are unwrapped using a 'branch cut' algorithm (Goldstein et al. 1988), and the resulting interferograms are then downsampled from millions to hundreds of data points using a quadtree decomposition algorithm (e.g. Jonsson et al. 2002). 3 arcsec Shuttle Radar Topography Mission data (Farr et al. 2007), are used to correct for topographic effects and to geocode the interferograms.

\section{SYNTHETIC TESTS}

To investigate the benefits of joint source inversions in the presence of data noise and of lateral heterogeneity we start by carrying out synthetic tests. Three fictitious events are considered, with varying magnitude and faulting mechanisms-normal $\left(M_{\mathrm{w}} 6.0\right)$, strike-slip ( $\left.M_{\mathrm{w}} 6.6\right)$, and thrust $\left(M_{\mathrm{w}} 6.5\right)$. Specifically, the input source parameters used to generate the synthetic data are based on previous studies of the three earthquakes investigated later in this study, to ensure that the tests are as realistic as possible. This includes the moderate magnitude normal faulting event in Eureka Valley in northern California, 1993 May 17, $M_{\mathrm{w}} 6.1$ (Massonnet \& Feigl 1995; 
(a) LPS Z

(b) LPS T

(c) LPS L

(d) LPB Z

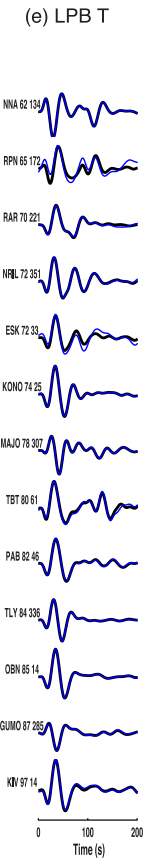

"มs"

rusus

จовต"

"wsssign

$\frac{\substack{500 \\ \text { Time(s) }}}{1000}$

xvert"

Aroor

wosioxy

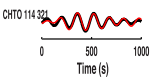

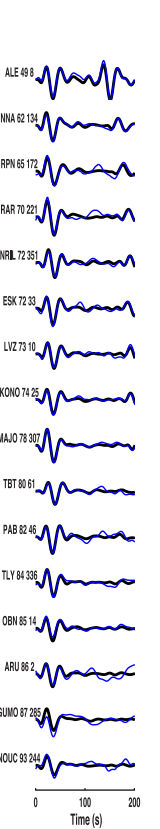

(f) LPB L
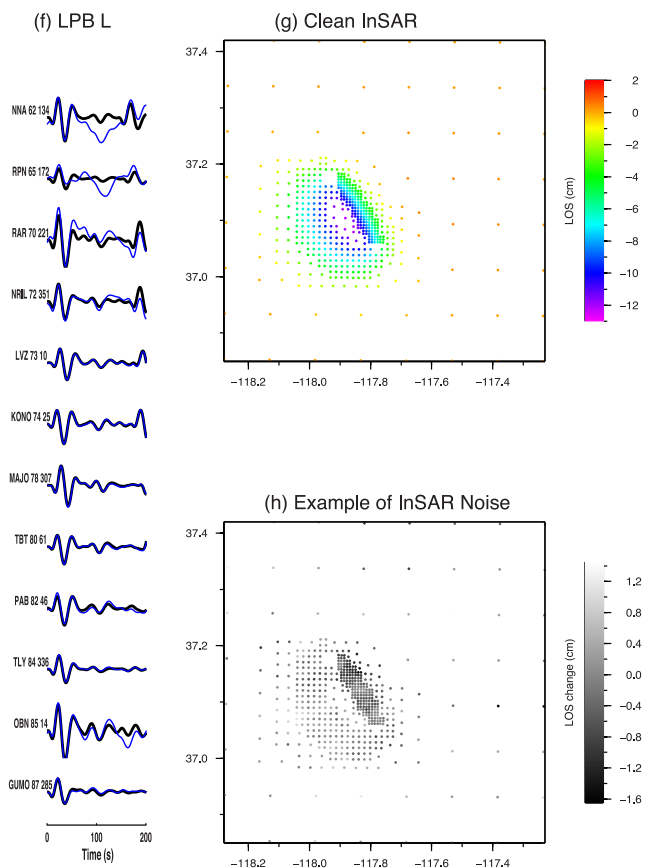

2
0
-2
-4
-6
-6
-8
-10
-12


1.2
0.8
0.4
0.0
-0.4
-0.8
-1.2
-1.6

Figure 3. Example of the synthetic data used in the tests, where the data shown are for a normal faulting earthquake $\left(M_{\mathrm{w}} 6.0,1\right.$ at: $37.092^{\circ}, 10 n:-117.930^{\circ}$, depth: $8 \mathrm{~km}$ ). (a)-(f) show the pure synthetics with no noise (black) and synthetic data with characteristic noise added for surface waves (red) and body waves (blue). (g) Quadtreed synthetic LOS displacements with no noise (h) LOS displacements added to those in (g) to perturb the data.

Weston et al. 2012), as well as a larger strike-slip event near the town of Aiquile, Bolivia, 1998 May 22, $M_{\mathrm{w}} 6.6$ (Funning et al. 2005; Devlin et al. 2012), and finally an equally large thrust faulting event in southcentral Iran, near the town of Zarand, 2005 February 22, $M_{\mathrm{W}}$ 6.5 (Talebian et al. 2006). The synthetic InSAR and seismic data are calculated using the same approaches outlined in Sections 2.1 and 2.2 , respectively.

Tests were first carried out using purely synthetic data (i.e. with no noise added) for all three artificial earthquakes to verify the technique, and in all the cases the input model is fully recovered in both individual data set and joint inversions. Real observations often have some noise incorporated in the signal; for example, vegetation or changes in land-use can result in decorrelation in the interferogram. The presence of water vapour or mountainous topography can also introduce artifacts or biases to interferograms, potentially masking or modifying the signal purely due to coseismic displacement. Seismic data, on the other hand, are sensitive to lunar tides, storms and human activity, all of which create reverberations in the crust and add a level of background noise to a seismogram. To add realistic noise to the synthetic seismograms, characteristic real noise recorded at each station during a period of no significant seismic activity is filtered for the same wave periods used for the surface and body waves and is added to the clean synthetics, an approach similar to that used in Hjörleifsdóttir \& Ekström (2009). Realistic noise for the InSAR 'data' is synthesized based on the length scale of spatial correlation of noise in a real interferogram (e.g. Hanssen 2001; Wright et al. 2003; Lohman \& Simons 2005). The 'data' in this case refer to the 'quadtreed' forward modelled LOS displacements, which are shown in Fig. 3 along with examples of noisy synthetic seismic data. These noisy synthetic data sets are subsequently the input data for the inversion, described in the previous section.
In order to estimate uncertainties and investigate trade-offs between the various source parameters, 100 such perturbed (i.e. noisy) synthetic data sets are generated. These 100 data sets are then inverted using the optimization scheme explained above. While the distributions of the various source parameters can thus be obtained to estimate their uncertainties, scatter plots of pairs of source parameters are useful to qualitatively assess the trade-offs or covariances between the parameters.

\subsection{Effect of data noise}

Table 1 shows the results from the synthetic tests in the presence of realistic noise for the normal, strike-slip and thrust earthquakes considered. In all cases the joint inversion of InSAR and long-period surface and body waves recovers a source model which overall is closest to the input source model than in separate inversions using an individual data type. Strike, dip and rake values from the various separate and joint inversions all vary within $\pm 1^{\circ}$ from the correct solution. In addition, the deviations from the input model are of about $\pm 1 \mathrm{~km}$ for the fault width and length, and about $\pm 0.2 \times 10^{18} \mathrm{Nm}$ for the seismic moment. The results from inversions of 100 sets of perturbed synthetic data and the corresponding trade-off plot show that for the normal faulting synthetic earthquake, all the source parameters are better resolved in the joint inversion (pink dots in trade-off plots in Fig. 4a) than in the InSAR-only (blue dots, Fig. 4a) and seismic-only inversion (black dots, Fig. 4b). The same trend is evident for the strike-slip and thrust faulting tests shown in Figs S2 and S3, respectively (see the supplementary materials). In all three trade-off plots, the source parameters from the joint inversions appear as tighter clusters in these scatter plots and narrower peaks in the histograms than the results from the separate data inversions. 
Table 1. Summary of results from the three synthetic tests; normal, strike-slip and thrust faulting events. The input models used to calculate the synthetic data are shown in bold italics, where the latitude, longitude and depth refer to the centroid location. Parameters fixed during the inversion are shown in bold, and $\mathrm{m}^{2}$ refers to the $\mathrm{L}_{2}$-norm misfit (see text and equation 4 for more detail). LPS refers to long-period surface waves and LPB to long-period body waves. For the thrust test the subscripts asc and $\mathrm{dsc}$ refer to ascending and descending InSAR data, respectively.

\begin{tabular}{|c|c|c|c|c|c|c|c|c|c|c|c|}
\hline Study & Mo $\left(\times 10^{18} \mathrm{Nm}\right)$ & Lat ${ }^{(0)}$ & Lon $(0)$ & Depth $(\mathrm{km})$ & Strike ${ }^{(0)}$ & $\operatorname{Dip}(0)$ & Rake ${ }^{(0)}$ & Slip $(\mathrm{m})$ & Length $(\mathrm{km})$ & Width $(\mathrm{km})$ & $\mathrm{m}^{2}$ \\
\hline Solution & 1.76 & 37.092 & -117.930 & 7.25 & 155.0 & 35.0 & -89.0 & 0.3 & 15.0 & 13.0 & \\
\hline InSAR & 1.66 & 37.095 & -117.932 & 7.28 & 153.6 & 36.6 & -100.0 & 0.28 & 14.6 & 13.4 & 0.004 \\
\hline LPS & 1.87 & 37.092 & -117.930 & 12.0 & 152.7 & 31.9 & -95.0 & 0.29 & 15.0 & 14.2 & 0.18 \\
\hline LPB & 1.69 & 37.092 & -117.930 & 12.0 & 153.5 & 34.4 & -91.1 & 0.28 & 15.0 & 13.3 & 0.14 \\
\hline LPS, LPB & 1.73 & 37.092 & -117.930 & 12.0 & 154.3 & 34.6 & -90.7 & 0.29 & 15.0 & 13.2 & 0.29 \\
\hline InSAR, LPS & 1.9 & 37.091 & -117.936 & 7.64 & 153.8 & 36.1 & -95.2 & 0.28 & 14.8 & 14.1 & 0.008 \\
\hline InSAR, LPB & 1.79 & 37.090 & -117.934 & 7.4 & 153.9 & 35.2 & -91.9 & 0.28 & 14.9 & 14.2 & 0.008 \\
\hline InSAR, LPS, LPB & 1.79 & 37.090 & -117.934 & 7.41 & 154.0 & 35.1 & -91.9 & 0.28 & 14.9 & 14.2 & 0.012 \\
\hline Solution & 9.0 & -17.903 & -65.186 & 8.4 & 10.0 & 80.0 & 175.0 & 1.0 & 20.0 & 15.0 & \\
\hline InSAR & 9.39 & -17.904 & -65.189 & 8.4 & 9.3 & 82.8 & 175.2 & 1.1 & 19.9 & 14.9 & 0.016 \\
\hline LPS & 9.2 & -17.903 & -65.186 & 12.0 & 9.6 & 73.3 & 177.0 & 0.99 & 20.0 & 15.4 & 0.060 \\
\hline LPB & 8.7 & -17.903 & -65.186 & 12.0 & 10.0 & 79.3 & 172.0 & 0.96 & 20.0 & 15.0 & 0.19 \\
\hline LPS, LPB & 8.96 & -17.903 & -65.186 & 12.0 & 9.4 & 79.2 & 172.8 & 0.99 & 20.0 & 15.0 & 0.12 \\
\hline InSAR, LPS & 8.91 & -17.905 & -65.188 & 8.1 & 9.4 & 81.9 & 175.0 & 1.1 & 19.9 & 14.3 & 0.033 \\
\hline InSAR, LPB & 8.67 & -17.905 & -65.184 & 8.2 & 9.3 & 78.9 & 174.8 & 0.98 & 19.9 & 14.9 & 0.034 \\
\hline InSAR, LPS, LPB & 8.90 & -17.905 & -65.183 & 8.5 & 9.3 & 79.2 & 174.8 & 0.97 & 19.9 & 15.4 & 0.041 \\
\hline Solution & 6.43 & 30.75 & 56.80 & 6.6 & 266.0 & 67.0 & 105.0 & 1.7 & 12.5 & 10.1 & \\
\hline $\operatorname{InSAR}_{d s c}$ & 7.23 & 30.750 & 56.798 & 6.8 & 266.3 & 66.5 & 114.9 & 1.86 & 12.5 & 10.4 & 0.0005 \\
\hline $\operatorname{InSAR} a s c$ & 6.48 & 30,754 & 56.792 & 5.6 & 266.1 & 58.4 & 140.0 & 1.76 & 13.0 & 9.5 & 0.0030 \\
\hline $\operatorname{InSAR}_{a s c \& d s c}$ & 6.74 & & & 6.97 & 266.3 & 66.9 & 104.6 & 1.66 & 12.5 & 10.8 & 0.0075 \\
\hline LPS & 6.37 & 30.75 & 56.80 & 12.0 & 264.3 & 65.6 & 105.2 & 1.67 & 12.5 & 10.2 & 0.11 \\
\hline LPB & 6.13 & 30.75 & 56.80 & 12.0 & 265.3 & 69.1 & 107.6 & 1.64 & 12.5 & 10.0 & 0.20 \\
\hline LPS, LPB & 6.48 & 30.75 & 56.80 & 12.0 & 264.8 & 67.0 & 104.8 & 1.71 & 12.5 & 10.1 & 0.21 \\
\hline InSAR, LPS & 5.58 & 30.746 & 56.803 & 5.7 & 266.4 & 66.9 & 104.7 & 2.04 & 12.6 & 7.2 & 0.0029 \\
\hline InSAR, LPB & 5.71 & 30.743 & 56.803 & 5.7 & 266.4 & 68.3 & 106.1 & 2.15 & 12.5 & 7.1 & 0.0029 \\
\hline InSAR, LPS, LPB & 6.27 & 30.750 & 56.802 & 6.5 & 266.3 & 66.1 & 105.5 & 1.71 & 12.5 & 9.8 & 0.0016 \\
\hline
\end{tabular}

Thus, our new joint inversion technique is shown to reduce the level of trade-offs in the presence of data noise. There is a distinct improvement when determining the fault rake angle, which shows wide variation in both the separate InSAR and seismic inversions. For all three artificial earthquakes considered, the moment and dip are also better constrained in the joint inversions, particularly for the normal and strike-slip synthetic tests, where trade-offs between the two parameters are evident in the seismic-only inversions (Figs 4 and S2).

\subsection{Effect of 3-D Earth structure}

It is clear from Fig. 1 that there are large differences between the 1-D and 3-D Earth models used in this study. Most notably the $P$-wave arrivals are earlier and the amplitudes smaller for the 1-D kernels (Figs 1d-f) and also some of the surface wave amplitudes are smaller than 3-D kernels, particularly for transverse component Love waves, for the source-receiver paths shown (Fig. 1b). Therefore to test the importance of the Earth model used and its effect on the inversions, separate and joint synthetic source inversions are carried out for a $M_{\mathrm{w}} 6.0$ normal faulting earthquake (top row of
Table 1), using both the 1-D and 3-D excitation kernels, and the method described in Section 4.1 above. The global Earth model used in this study is relatively smooth (e.g. it does not incorporate sharp discontinuities) and might be subject to improvements in future studies. Nevertheless, the model used is a good approximation for the long-period seismic data used in this study. Moreover, it is a widely used model in seismological applications, with largescale features common to other existing tomographic models (e.g. Schaeffer \& Lebedev 2013). Thus, the effects of a 3-D Earth structure on the inversions estimated using this model are likely representative.

Separate seismic inversions (LPS and LPB) and joint inversions are carried out using the two sets of seismic moment tensor excitation kernels. The top panel of Table 1 and Table 2 show results using 3-D and 1-D excitation kernels, respectively. As expected, the seismic-only inversions assuming a 3-D Earth structure show a misfit to the data much lower than when assuming a 1-D structure. The joint source inversion results follow the same trend, with the solutions obtained using the 3-D excitation kernels leading to an improved fit of the seismic and InSAR data (Figs 5b, d, f and i) than results from inversions using 1-D excitation kernels (Figs 5a, 
a)
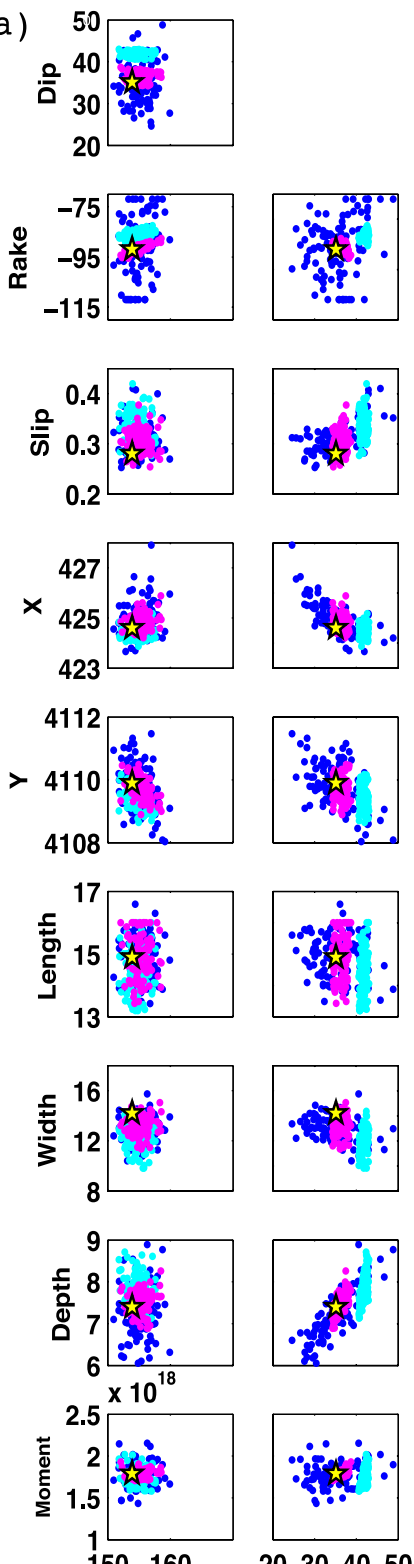

150160

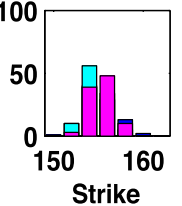

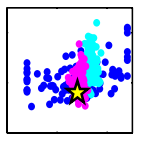
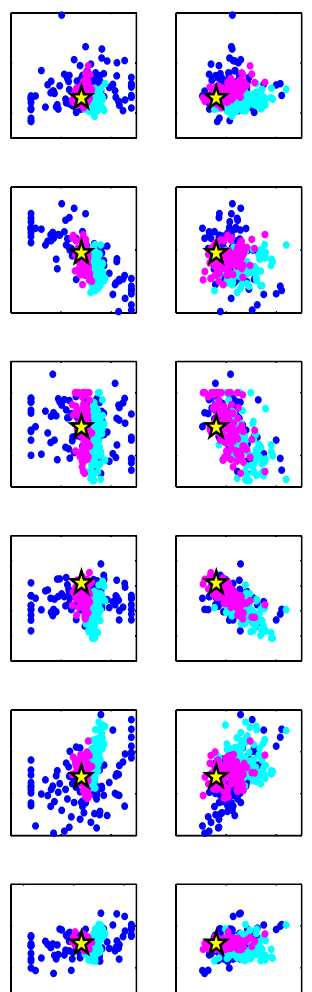

$20304050-115-95-75$
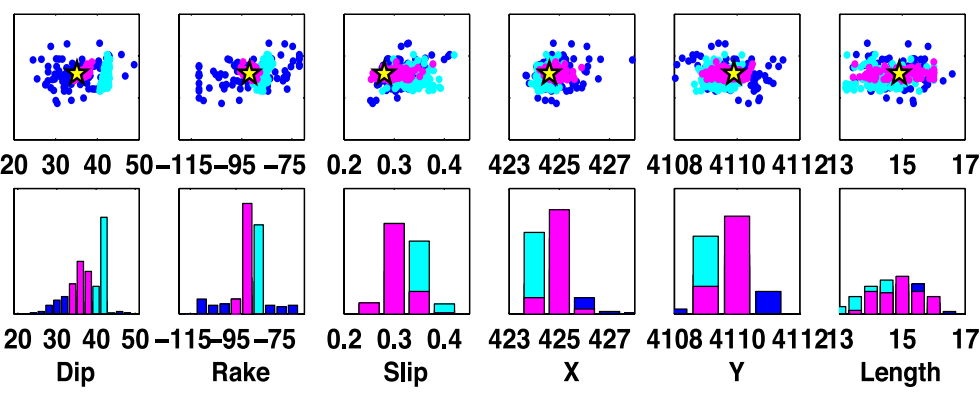
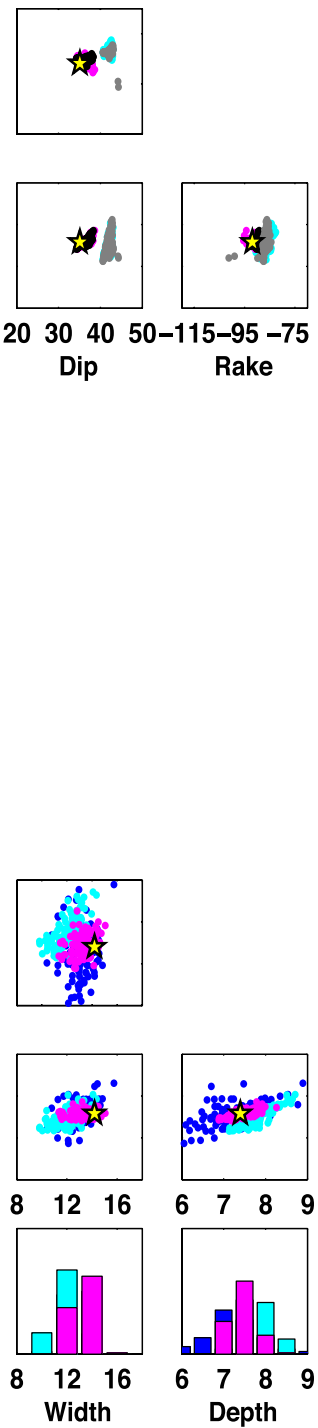

$\begin{array}{llll}6 & 7 & 8 & 9\end{array}$

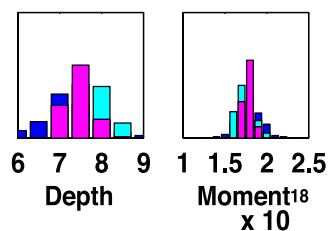

Figure 4. (a) Trade-off scatterplots and histograms for the InSAR only inversion (blue) and joint source inversions using 1-D (cyan) and 3-D (pink) excitation kernels, for a synthetic normal faulting event. The scatterplots show the best-fitting source parameters from 100 inversions using 100 data sets which have been perturbed slightly by characteristic noise. Strike, dip and rake are in degrees, Moment is in Nm, slip in m, and length, width and depth in kilometres. $X$ and $Y$ refer to the centroid projected updip to the surface and are given in UTM kilometres rather than degrees to better illustrate the variations. The histograms show the distribution of the inversion results to illustrate the uncertainties for each parameter and the focal mechanism at the top refers to the input model, the parameters of which are denoted by the yellow star on the trade-off plots. (b) Trade-off scatterplot for seismic-only inversion using 1-D (grey) and 3-D (black) excitation kernels. Only moment, strike, dip and rake were inverted for as all other parameters were fixed in the seismic-only inversions. 
Table 2. Summary of source inversion results for a synthetic normal faulting earthquake $\left(M_{W} 6.0\right)$, where the kernels were calculated assuming a 1-D Earth structure, while input synthetic data were built using the 3-D crustal model CRUST2.0 combined with the 3-D mantle model S40RTS. Format is the same as in Table 1.

\begin{tabular}{|c|c|c|c|c|c|c|c|c|c|c|c|}
\hline Study & Mo $\left(x 10^{18} \mathrm{Nm}\right)$ & Lat $(0)$ & Lon ${ }^{(\circ)}$ & Depth $(\mathrm{km})$ & Strike ${ }^{(\circ)}$ & $\operatorname{Dip}^{(\circ)}$ & Rake $^{(0)}$ & Slip (m) & Length $(\mathrm{km})$ & Width $(\mathrm{km})$ & $\mathrm{m}^{2}$ \\
\hline Solution & 1.76 & 37.092 & -117.930 & 7.25 & 155.0 & 35.0 & -89.0 & 0.3 & 15.0 & 13.0 & - \\
\hline LPS & 1.63 & 37.092 & -117.930 & 12.0 & 136.5 & 50.03 & -114.7 & 0.37 & 15.0 & 9.8 & 0.320 \\
\hline LPB & 1.61 & 37.092 & -117.930 & 12.0 & 152.8 & 40.7 & -87.8 & 0.31 & 15.0 & 11.5 & 0.600 \\
\hline LPS, LPB & 1.58 & 37.092 & -117.930 & 12.0 & 155.2 & 40.8 & -88.4 & 0.31 & 15.0 & 11.5 & 0.630 \\
\hline InSAR, LPS & 1.73 & 37.087 & -117.948 & 7.4 & 153.6 & 31.6 & -99.1 & 0.24 & 17.0 & 14.02 & 0.013 \\
\hline InSAR, LPB & 1.88 & 37.092 & -117.930 & 8.2 & 153.9 & 40.4 & -90.9 & 0.31 & 14.6 & 14.0 & 0.013 \\
\hline InSAR, LPS, LPB & 1.84 & 37.094 & -117.930 & 8.0 & 153.9 & 39.7 & -92.5 & 0.30 & 14.7 & 13.8 & 0.008 \\
\hline
\end{tabular}

(a) PREM LPS Z

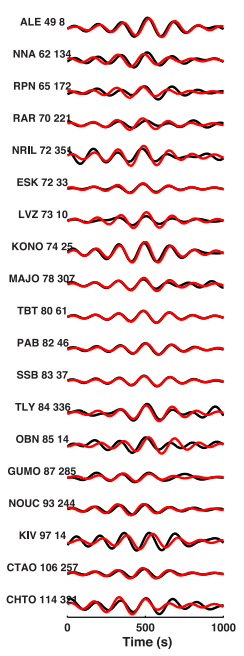

(b) S40RTS LPS Z

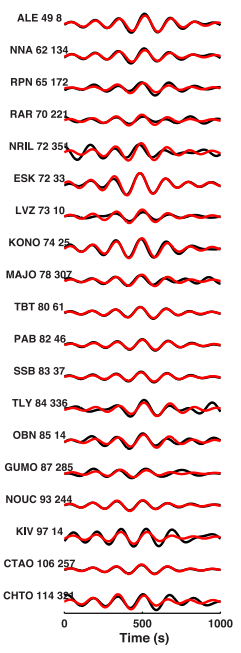

(g) Data

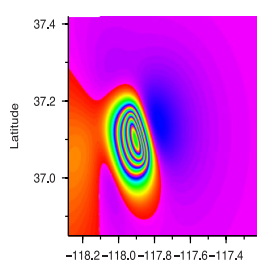

(c) PREM LPB Z

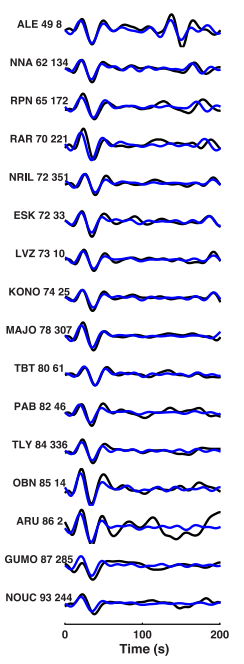

(h) PREM

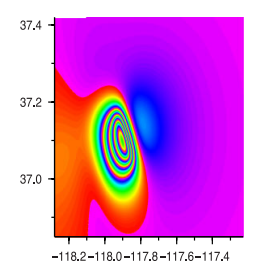

(d) S4ORTS LPB Z

(e) PREM LPB T

(f) S40RTS LPB T

Figure 5. Comparison of the fit of joint source inversion results calculated using a 3-D and 1-D excitation kernels for a synthetic normal faulting event. (a)-(b) Show the vertical components for long-period surface waves, 1-D and 3-D results, respectively. The synthetic input data are shown in black and the joint inversion synthetics are in red. (c)-(d) Shows results for body waves (synthetics in blue), the vertical component and (e)-(f) the transverse components. (g) Synthetic interferogram used as 'input data' in both joint inversions which use 1-D or 3-D kernels. (h) Interferogram calculated using the results from the joint inversion which uses 1-D kernels. (i) Same as in (h) except the source model from the joint inversion using 3-D kernels is used in the forward modelling of the interferogram.

c, e and g). Furthermore, in both the 1-D and 3-D Earth model tests, the body wave inversions recover the input source parameters more robustly than the surface wave inversions, with the differences between the surface and body wave inversion results being more pro- nounced when using 1-D kernels. In particular, the best-fitting fault dips from the $1-\mathrm{D}$ inversions are $10^{\circ}-15^{\circ}$ steeper than in the input source model. This difference in the recovery of the fault dip angle is clearly marked out in the trade-off plot in Fig. 4. Moreover, Fig. 4 

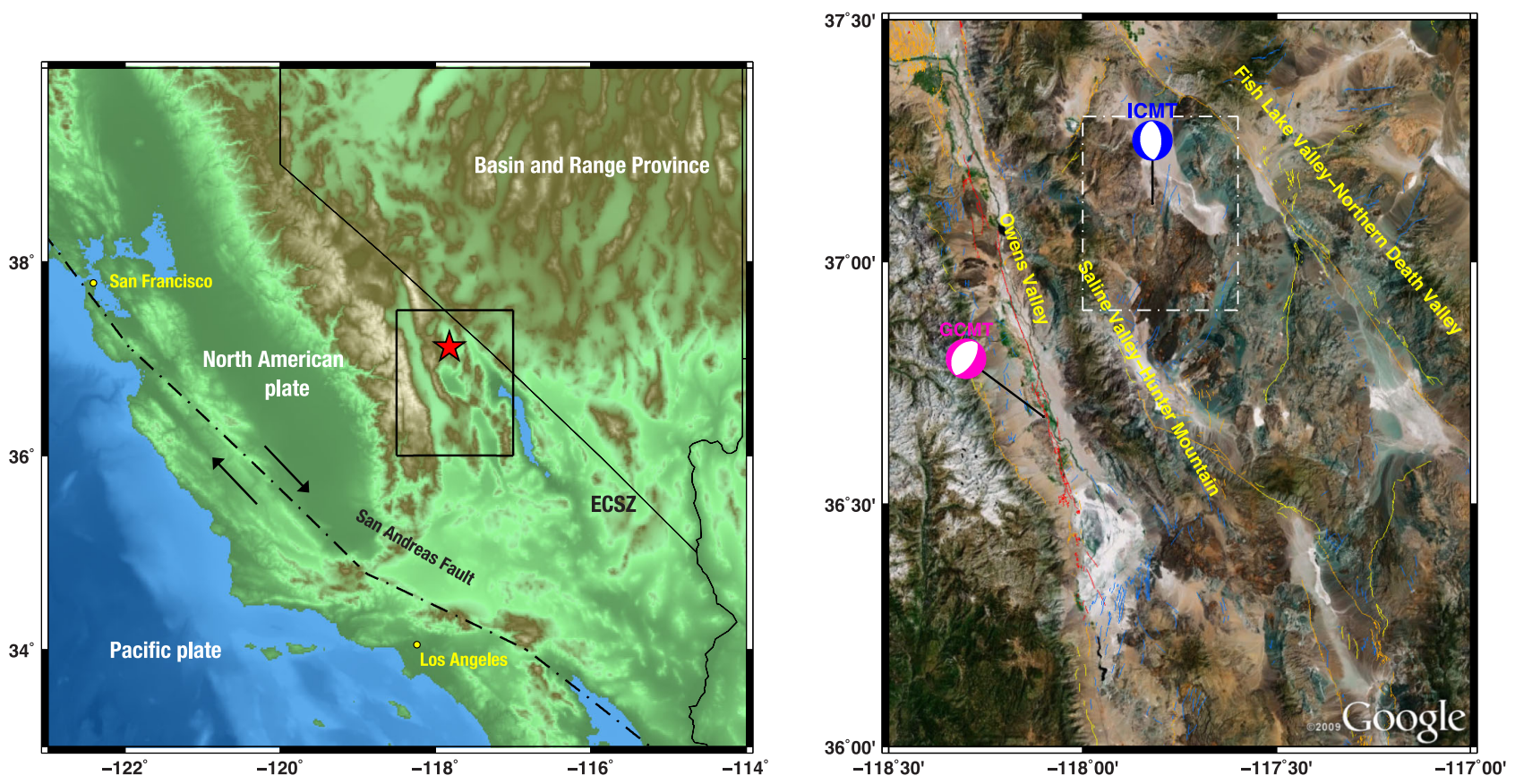

Figure 6. Map on the left provides an overview of the overall tectonic setting of northern California, due to the movement of the Pacific and North American plates. The Eureka Valley earthquake is denoted by the red star, and the black square refers to the map on the right, which shows the relevant fault zones highlighted in yellow (based on United States Geological Survey fault maps, USGS, 2011). Focal mechanisms for the event from the GCMT catalogue and results in this study (ICMT) are shown in pink and blue, respectively, and the dashed white box corresponds to the area covered by the InSAR data in Fig. 7. It should be noted that that there are $55 \mathrm{~km}$ between the ICMT and GCMT locations.

shows that the 1-D Earth results (cyan dots) are much less tightly clustered in comparison with 3-D Earth inversion results (pink dots), with stronger trade-offs than in the 3-D Earth inversions.

\section{CASE STUDY: EUREKA VALLEY, $M_{\mathrm{w}}$ 6.1, 1993 MAY 17}

The Eureka Valley, California, earthquake was part of a sequence of events including the large strike-slip Landers earthquake $\left(M_{\mathrm{W}}\right.$ 7.3, 1992 June 26). The Eureka Valley is on the California-Nevada border, within the Basin and Range Province (Fig. 6). Regional extension plays an important role in accommodating the deformation within the Pacific-North American Plate boundary zone (e.g. Atwater 1970). The 1993 event is thought to have occurred on a buried normal fault which is one of five currently known normal fault zones between the Panamint Valley-Hunter Mountain-Saline Valley fault system and the Furnace Creek and Fish Lake Valley faults (Oswald \& Wesnousky 2002). These fault systems make up part of the Eastern California Shear Zone, which is thought to accommodate the remaining relative motion between the Pacific and North American plates not taken up by the San Andreas fault system, west of the Sierra Nevada (e.g. Atwater 1970).

The Eureka Valley earthquake $\left(M_{\mathrm{w}} 6.1\right)$ occurred at 23:20 (GMT) on 1993 May 17 and more than 500 aftershocks followed the event (Asad et al. 1999), including three aftershocks with magnitude $>4.5$ (Massonnet \& Feigl 1995). It was one of the first events to be measured using InSAR (see Table 3 for existing studies, Massonnet \& Feigl 1995; Peltzer \& Rosen 1995), and the quality of the geodetic data is very high; the coseismic signal is extremely clear due to low levels of atmospheric noise and high coherence. Hence strong constraints can be placed on the event's location and strike (see Fig. 7a). However, there is a large discrepancy of about $55 \mathrm{~km}$ between the earthquake's centroid location determined using InSAR
(Massonnet \& Feigl 1995) and that reported in the GCMT catalogue, which motivates this case study. By modelling the seismic data using the earthquake's location constrained by InSAR data alone and a different Earth model to the one employed by the GCMT catalogue, this case study investigates whether the two data sets can be reconciled.

A descending-track interferogram is calculated from two ERS-1 SAR images, spanning $525 \mathrm{~d}$, and is downsampled to 795 points (see Fig. 7a). The seismic data set comprises data from 17 seismic stations, including a total of 34 waveforms (18 LPS, 16 LPB; see Fig. 8).

Table 3 shows the results for the individual and joint earthquake source inversions. There is a clear moment-dip trade-off in the LPS inversion but the fault strike estimated using long-period surface waves is relatively close to that found using InSAR data $\left(181.9^{\circ}\right)$ and this north-south strike is in agreement with existing studies (Massonnet \& Feigl 1995; Peltzer \& Rosen 1995; Asad et al. 1999). However, the long-period body wave inversion favours a more northeast to southwest trending strike $\left(212.1^{\circ}\right)$, which is consistent with the GCMT estimate. Despite these discrepancies, when all three data sets are combined the dip is a compromise between the slightly steeper angle suggested by geodetic data and the shallower values preferred by the seismic data. Overall the fit of the joint inversion result to the InSAR data is reasonable (Figs $7 b$ and c) with no obvious fringes present in the residual interferogram (the difference between the data and forward modelled result). The more northeasterly strike favoured in the body wave inversion is also tested (Fig. 7d) and although the shape of the deformation signal is similar to the data, its orientation results in a mislocation of the pattern and consequently high residuals (Fig. 7e). The joint inversion solution fits the seismic data reasonably well (Fig. 8). For a few stations there is a slight underestimation of the surface wave amplitudes (e.g. stations NNA, TLY, CHTO, Figs 8a and b). However, the 
Table 3. Summary of source inversion results for the $\mathrm{M}_{\mathrm{w}}$ 6.1 Eureka Valley earthquake. Models from previous studies are listed in the top lines, where dashed lines indicate the parameters that were not available in the studies. Results from this study are listed below the existing studies. The latitude, longitude and depth refer to the centroid location and the misfit value $\left(\mathrm{m}^{2}\right)$ refers to an L2-norm misfit. Parameters fixed during the inversion are highlighted in bold. LPS refers to long period surface waves and LPB long period body waves.

\begin{tabular}{|c|c|c|c|c|c|c|c|c|c|c|c|c|}
\hline Model & $\begin{array}{c}\text { Mo } \\
\left(\times 10^{18} \mathrm{Nm}\right)\end{array}$ & $\begin{array}{l}\text { Lat. } \\
\left({ }^{\circ}\right)\end{array}$ & $\begin{array}{c}\text { Lon. } \\
\left({ }^{\circ}\right)\end{array}$ & $\begin{array}{c}\text { Depth } \\
(\mathrm{km})\end{array}$ & $\begin{array}{c}\text { Strike } \\
\left({ }^{\circ}\right)\end{array}$ & $\begin{array}{c}\text { Dip } \\
\left({ }^{\circ}\right)\end{array}$ & $\begin{array}{c}\text { Rake } \\
\left({ }^{\circ}\right)\end{array}$ & $\begin{array}{l}\text { Slip } \\
\text { (m) }\end{array}$ & $\begin{array}{c}\text { Length } \\
(\mathrm{km})\end{array}$ & $\begin{array}{c}\text { Width } \\
(\mathrm{km})\end{array}$ & $\begin{array}{c}\text { Misfit } \\
\mathrm{m}^{2}\end{array}$ & - \\
\hline Existing studies & & & & & & & & & & & & \\
\hline Massonet \& Feigl (1995) & 1.57 & 37.110 & -117.790 & 9.2 & 173.0 & 54.0 & & 0.43 & 16.4 & 7.4 & - & - \\
\hline Peltzer \& Rosen (1995) & - & - & - & 13.0 & 187.0 & 50.0 & - & - & 15.0 & 16.0 & - & \\
\hline Asad et al., (1999) & - & - & - & - & 165.0 & 60.0 & - & - & - & - & - & \\
\hline Ichinose et al., (2003) & - & - & - & - & 193.0 & 48.0 & -102.0 & - & - & - & - & \\
\hline Ritsema \& Lay & 1.4 & 37.200 & -117.800 & 10.0 & 37.0 & 49.0 & -66.0 & - & - & - & - & \\
\hline GCMT & 1.83 & 36.68 & -118.100 & 15.0 & 210.0 & 30.0 & -93.0 & - & - & - & - & \\
\hline \multicolumn{12}{|l|}{ This Study } & \\
\hline InSAR & 1.60 & 37.109 & -117.789 & 8.6 & 173.8 & 41.4 & -87.3 & 0.36 & 16.6 & 9.1 & 0.011 & \\
\hline LPS & 1.93 & 37.109 & -117.789 & 12.0 & 181.9 & 24.0 & -122.6 & 0.26 & 16.6 & 14.7 & 0.090 & \\
\hline LPB & 1.15 & 37.109 & -117.789 & 12.0 & 212.1 & 35.0 & -71.7 & 0.22 & 16.6 & 10.5 & 0.220 & \\
\hline LPS, LPB & 1.39 & 37.109 & -117.789 & 12.0 & 215.3 & 35.5 & -63.9 & 0.27 & 16.6 & 10.3 & 0.200 & \\
\hline InSAR, LPS & 1.39 & 37.126 & -117.786 & 8.5 & 173.5 & 51.3 & -113.2 & 0.66 & 11.0 & 6.3 & 0.051 & \\
\hline InSAR, LPB & 1.22 & 37.107 & -117.794 & 6.7 & 175.3 & 34.3 & -81.8 & 0.32 & 15.2 & 8.3 & 0.036 & \\
\hline InSAR, LPS, LPB & 1.18 & 37.114 & -117.793 & 6.7 & 175.3 & 35.5 & -94.4 & 0.33 & 15.0 & 7.9 & 0.049 & \\
\hline
\end{tabular}

$P$-wave arrivals are modelled well in the body wave comparisons (Figs $8 \mathrm{c}$ and d). Fig. 9 shows the trade-offs between the various source parameters for InSAR-only inversions (blue), seismic-only inversions (black) and joint inversions (pink). There is a slight tradeoff between strike and rake in the seismic-only inversions (Fig. 9b) but the rake is more tightly clustered than in the InSAR-only inversion. The joint inversion results overall are more tightly clustered than in the InSAR-only inversion, in particular for the fault dip angle and slip, but there is a clear trade-off between fault strike and rake and also between strike and latitude. These issues as well as comparisons with other existing source models are discussed in Section 8 .

6 CASE STUDY: AIQUILE, BOLIVIA, $M_{\mathrm{w}} 6.5,1998 \mathrm{MAY} 22$

The 1998 Aiquile, Bolivia, earthquake occurred in the Eastern Cordillera section of the Bolivian Andes (Fig. 10). The central Andes form the widest part of the mountain chain $(\sim 700 \mathrm{~km})$ and much of the topography reaches elevations of 3-4 km (Lamb 2000). This section of the Nazca-South American subduction zone is the focus of much research due to the bending of the Bolivian orocline. It is part of the orogenic belt at $\sim 17^{\circ} \mathrm{S}$, where there is an abrupt change in the strike of the mountain range. Palaeomagnetic and crustal deformation studies suggest that this bending has occurred in the last $10 \mathrm{Myr}$ (e.g. Isacks 1988; Lamb 2000; Roperch et al. 2000; McQuarrie 2002; Barke et al. 2007). GPS observations have also been interpreted as observations of the bending in real time (over the past two decades) at rates comparable to geological rates (Allmendinger et al. 2005). Presently the convergence of the Nazca-South American Plate is accommodated through the movement of the Bolivian Andes towards the continent's interior at $7-10 \mathrm{~mm} \mathrm{yr}^{-1}$ (Brooks et al. 2011). The regional tectonics are complicated and robust earthquake source models, particularly for strike-slip earthquakes may provide insights as to how the bending is accommodated and also the resulting changes in the stress regime, important for assessing the region's seismic hazard.

The $M_{\mathrm{w}} 6.6$ earthquake struck the mountainous region of Aiquile on 1998 May 22 at 04:48 (GMT); it resulted in over 100 deaths and caused severe damage to the village of Hoyadas and the nearby towns Aiquile and Totora (Funning et al. 2005). Locations reported in seismic catalogues (GCMT, ISC, EHB and NEIC) and studies with geodetic data (Funning et al. 2005; Devlin et al. 2012) show a wide variation (Table 4), which makes it difficult to identify the tectonic structure and mechanism responsible for the earthquake.

The InSAR data for this event are of poor quality due to high levels of noise and poor coherence due to vegetation and mountainous topography. Different studies have found the fault to be near vertical, but estimates based on geodetic data (Funning et al. 2005; Devlin et al. 2012) suggest a different dipping direction and also location ( $\sim 40 \mathrm{~km}$ south) to that reported in the GCMT catalogue. One descending interferogram spanning 821 days is calculated from SAR images taken using the ERS-2 satellite (Fig. 11a), the same image pair as that used in Funning et al. (2005); Devlin et al. (2012). The large measurement period, as well as the vegetation and slopes, 
(a)
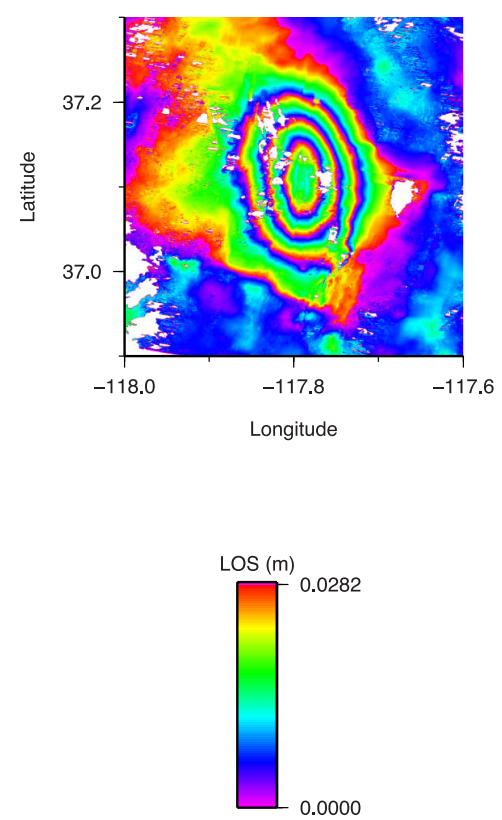

(b)

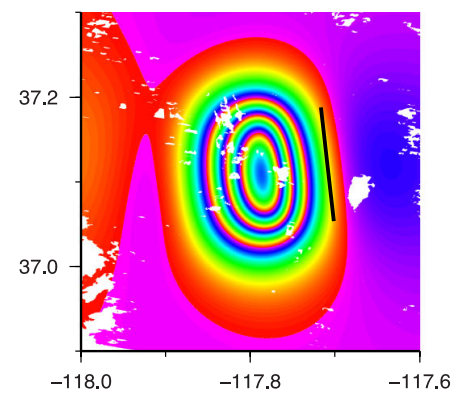

(d)

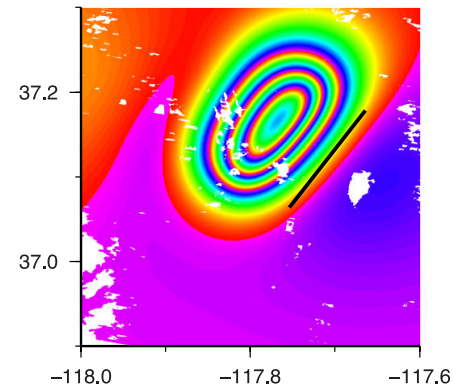

(c)

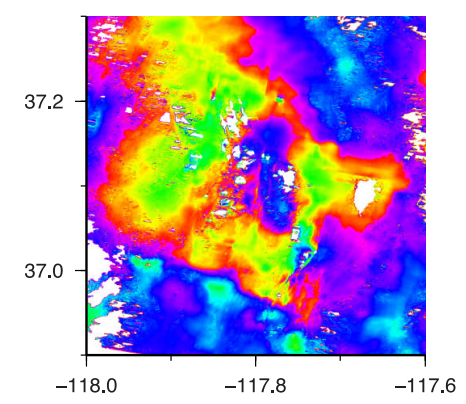

(e)

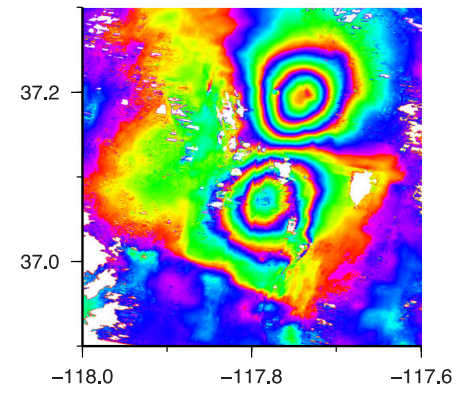

Figure 7. (a) Descending interferogram calculated from two ERS-1 images (1992 January 6 and 1993 August 11, Track 442) (b) Forward modelled interferogram using the joint inversion result for the $M_{\mathrm{w}} 6.1$ Eureka Valley earthquake listed in Table 3, where the updip projection of the top of the fault to the surface is denoted by the black line (c) Residual between interferogram (a) and forward modelled result (b). (d) Shows the interferogram calculated using the joint inversion results, except the strike has been replaced with the value from the body wave inversion, which shows large disagreement with the joint inversion result and existing studies (Table 3). The black line represent the updip projection of the top of the fault to the surface. (e) This is the residual between the model in (d) and the data in (a) which highlights the poor fit between this model and the data.

is probably responsible in part for the poor quality of the data and could include deformation signals due to events other than the earthquake. Seismic data from 38 stations are used, which results in a total of 86 waveforms (52 LPS, 34 LPB; see Fig. 12).

Separate inversions of all three data sets show a generally good agreement, favouring a steeply dipping N-S striking fault (Table 4). However, there is a clear moment-dip trade-off in the surface wave inversion, with the corresponding best-fitting model having a much shallower dip and the largest moment estimate of all inversion results. There is a larger thrust component in the rake in the preferred model from the body wave inversion, and combining the two seismic data sets results in a vertical fault with pure right lateral strike-slip. A combination of all three data sets introduces a trade-off between the width and slip; the fault width increases to $18 \mathrm{~km}$ and a reduction in slip compensates for this. The fit to the long-period surface waves is excellent (Figs 12a-c). For long-period body waves (Figs 12d-f), the data fit is still reasonable, but some phase shifts in $P$ and $S H$ wave arrivals are evident at some stations (e.g. stations SUR and PMSA in Fig. 12d and HKT and CCM in Fig. 12f). The InSAR data are fit reasonably well, particularly for the east side of the deformation pattern but there are four residual fringes to the southwest (Fig. 11c). This is partly due to the relatively short length of the fault $(L=14 \mathrm{~km})$ that is linked with the trade-offs between fault size and slip, which in turn influences dip (Fig. 13). In tests with added realistic noise both separate InSAR and seismic inversions favour a steeper dip of $80^{\circ}$ but in the joint inversion this is shifted to $50^{\circ}$. This is partly due to the poor quality of the InSAR data and is an issue which is discussed later. Despite these issues, it is clear that the fault's strike is much better constrained in the joint inversions than in the separate inversions (see Fig. 13, which shows that the results for the joint inversion are generally more tightly clustered than in the inversions of individual data sets).

\section{CASE STUDY: ZARAND, IRAN, $M_{\mathrm{w}} 6.5$,} 2005 FEBRUARY 22

The 2005 Zarand, Iran, earthquake occurred on a previously known fault in the Kerman province in southcentral Iran. This region is shortening due to the collision of the Arabian and Eurasian plates (Fig. 14), which are converging at a rate of $\sim 24 \mathrm{~mm} \mathrm{yr}^{-1}$ (e.g. Sella et al. 2002; Vernant et al. 2004). The fault is part of the Kuh Banan fault zone (Fig. 14); however, unusually, this reverse event occurred on a fault plane oblique to the edge of the mountain range, as defined by the Kuh Banan fault (Talebian et al. 2006). Furthermore, the seismic potential of this fault was underestimated due to its unclear geomorphological expression and lack of evidence for recent activity. This is thought to be due to the high levels of erosion as a result of winter rain, snow melt, and weak rocks. Triassic-Jurassic sediments, mostly comprised of sandstones and shales, make up much of the epicentral region (Talebian et al. 2006).

The $M_{\mathrm{w}} 6.5$ earthquake occurred at 02:25 (GMT) on the 2005 February 22, and resulted in more than 500 fatalities (Rouhollahi et al. 2012), only a year after the Bam earthquake, which ruptured a blind strike-slip fault further south (e.g. Talebian et al. 2004), and resulted in more than 30000 fatalities (USGS 2010). These two earthquakes on blind faults highlight the difficulty of estimating the seismic hazard in this region. Therefore, robust source models are beneficial for gaining insight into the tectonic processes driving 
(a) LPS Z
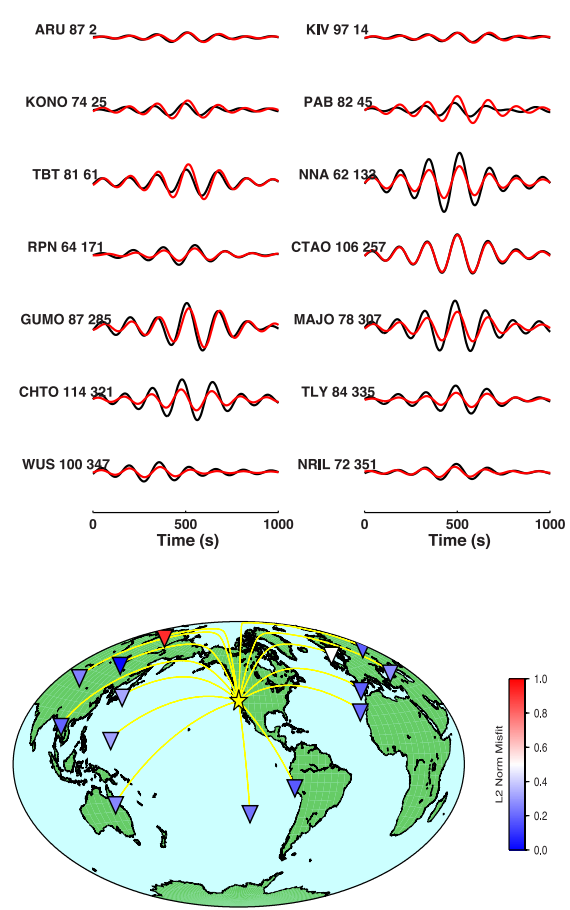

(c) LPB Z
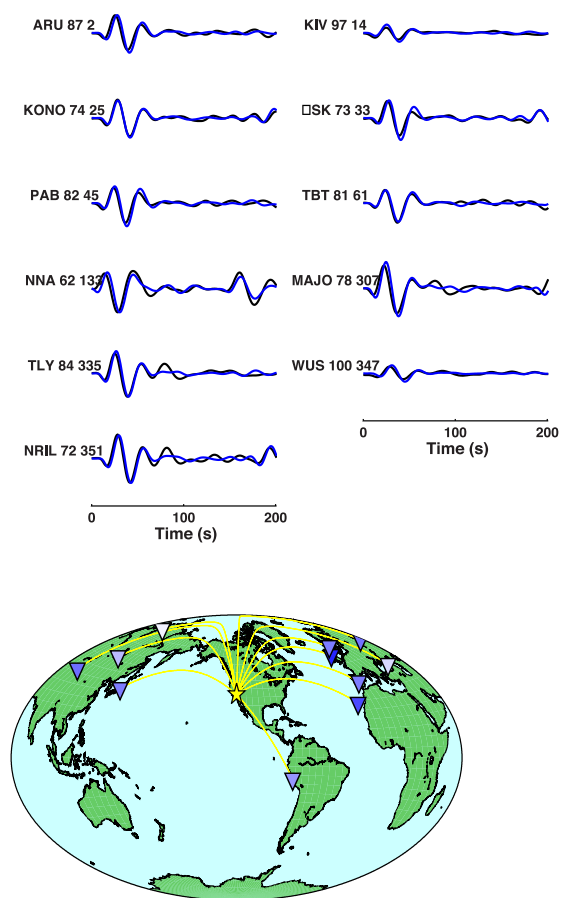

(b) LPS T

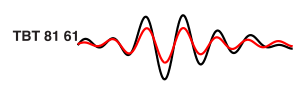

NNA213n

MAJ0 7830z
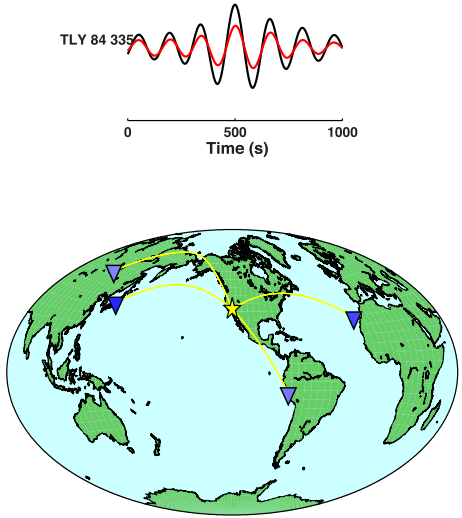

(d) LPB L
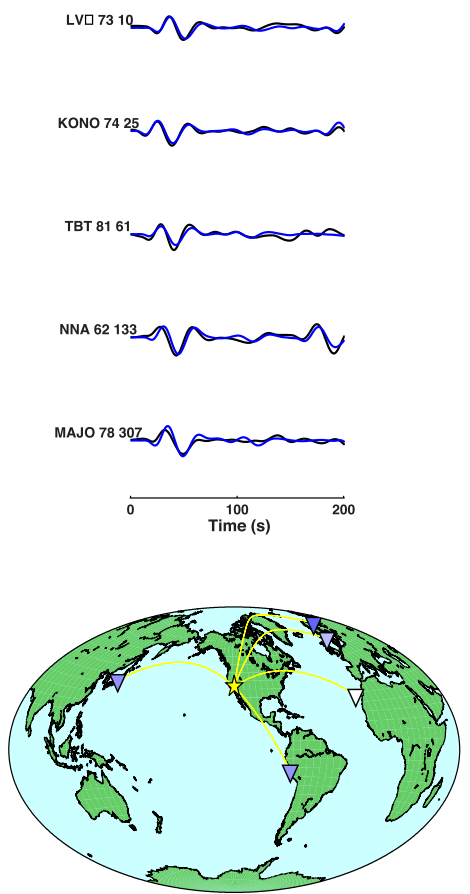

Figure 8. (a) Fit of joint inversion results for the $M_{\mathrm{W}} 6.0$ Eureka Valley earthquake (red) to the data (black), filtered for LPS where the vertical component $(Z)$ is shown. The station name, epicentral distance and azimuth are shown next to each waveform and the map below shows the station distribution and its corresponding misfit to the data, where the misfit colour scale is the same for all four maps. Great circle paths are shown in yellow and the yellow star denotes the earthquake location. (b) The same as (a) but for the transverse (T) component. (c)-(d) Show the fit of the LPB results (blue) to the data, for the vertical (Z) and longitudinal (L) components, respectively, and follow the same format as (a). 


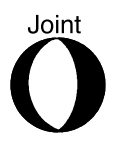

a)
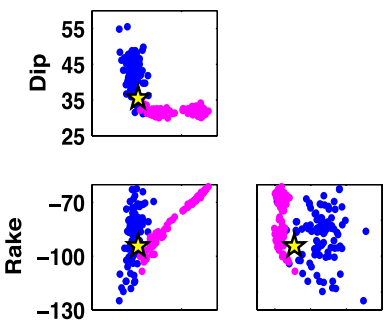

b)
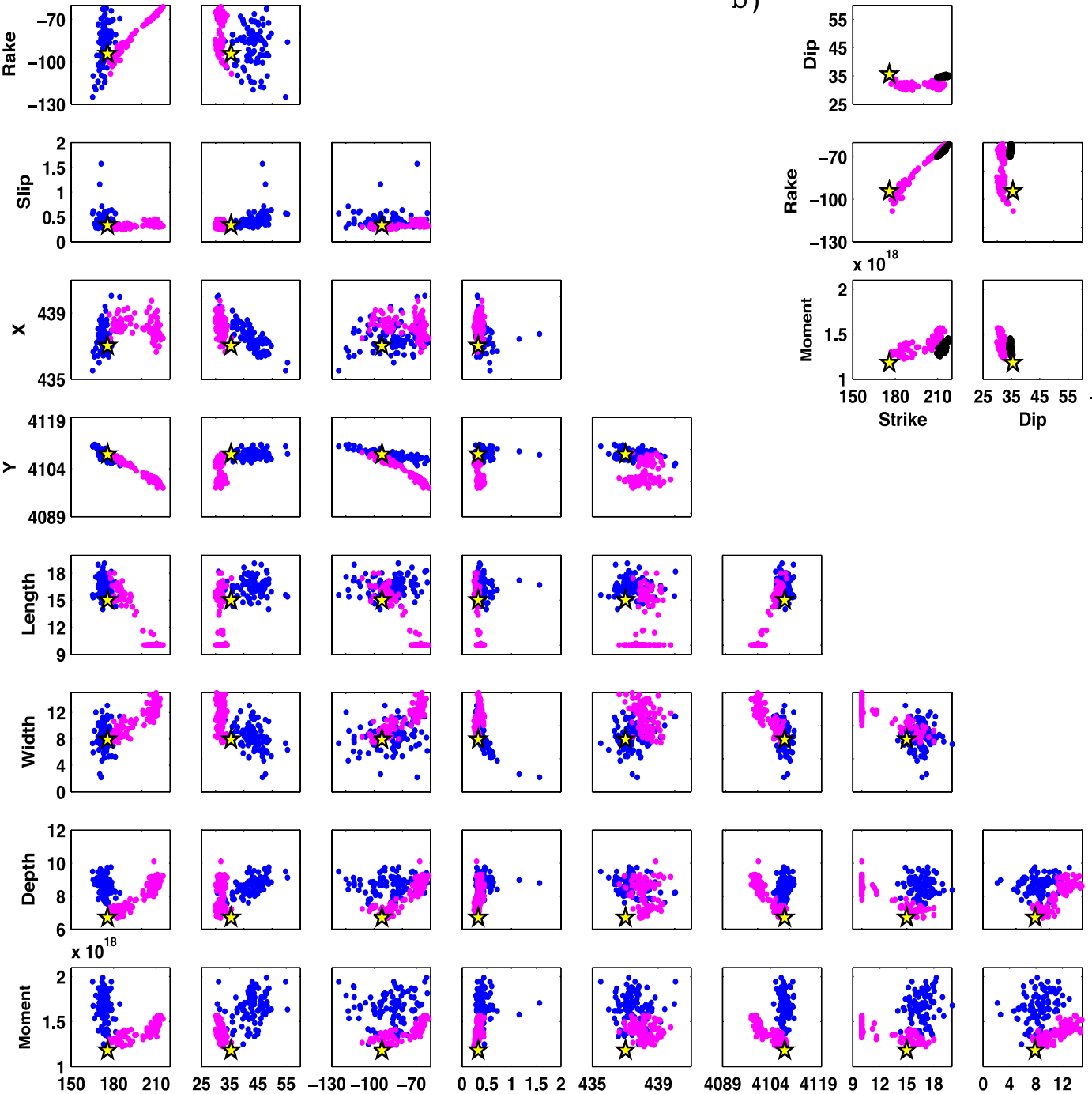

00.511 .52435
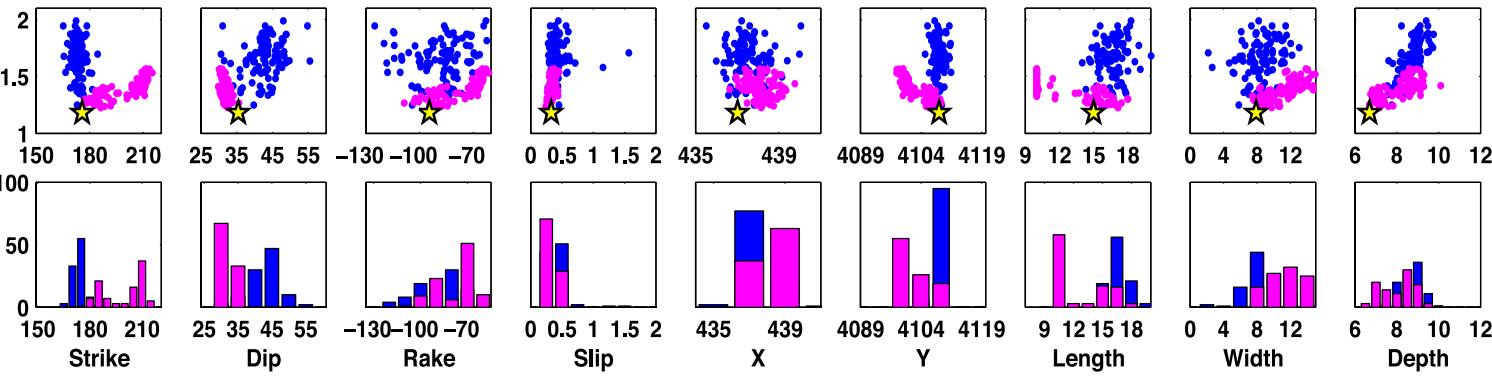

Figure 9. (a) Trade-off scatterplots for InSAR only inversion (blue) and joint source inversion (pink) for the $M_{\mathrm{w}} 6.0$ Eureka Valley earthquake, with the focal mechanism from the joint source inversion shown in pink at the top, and the parameters of which are denoted by the yellow stars. (b) Trade-off scatterplots for the seismic-only inversion (black) and the joint inversion. Format is same as in Fig. 4.

the deformation in this region, and consequently achieve a better understanding of the potential for future earthquakes.

Two interferograms (ascending and descending) calculated using images from ENVISAT were available for this event (Figs 15a and b). However, both interferograms are decorrelated near the fault due to steep terrain, possible snow, coseismic ground shaking, and landslides (Talebian et al. 2006). The dip reported by the GCMT catalogue is much shallower than those reported by existing studies (Table 5, Talebian et al. 2006; Rouhollahi et al. 2012). This event is the most recent of all the three case studies and the second highest in moment magnitude. A total of 92 seismic waveforms are used (46 LPS, 46 LPB) from 36 stations (see Fig. 16). It should be noted 

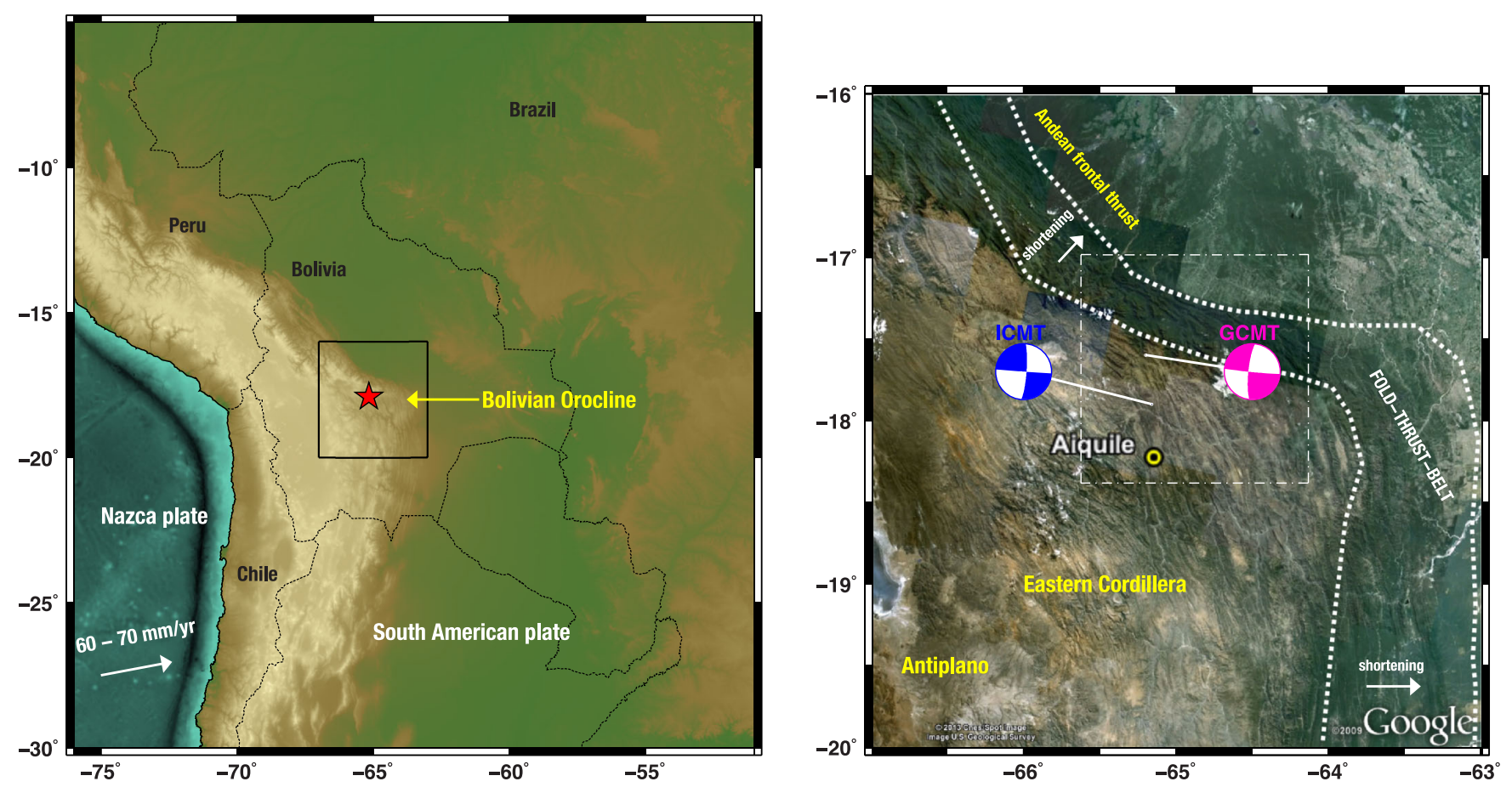

Figure 10. Tectonic setting for the $M_{\mathrm{w}} 6.6$ Aiquile, Bolivia earthquake, denoted by the red star in the map on the left. The black box refers to the figure on the right which shows the focal mechanisms from the GCMT catalogue and this study (ICMT) in pink and blue, respectively. The location of town of Aiquile is shown by the yellow circle and the dashed white box refers to the area covered by the InSAR data shown in Fig. 11. The high central plateau known as the Antiplano and the more rugged region of the Eastern Cordillera, which reaches heights of $6.5 \mathrm{~km}(\mathrm{Lamb}, 2000)$ and forms part of the Bolivian Andes, are also highlighted.

Table 4. Summary of source inversion results for the $\mathrm{M}_{\mathrm{w}} 6.6$ Aiquile earthquake. Format is same as in Table 3.

\begin{tabular}{|c|c|c|c|c|c|c|c|c|c|c|c|c|}
\hline Model & $\begin{array}{c}\text { Mo } \\
\left(\times 10^{18} \mathrm{Nm}\right)\end{array}$ & $\begin{array}{c}\text { Lat. } \\
\left({ }^{\circ}\right)\end{array}$ & $\begin{array}{c}\text { Lon. } \\
\left({ }^{\circ}\right)\end{array}$ & $\begin{array}{c}\text { Depth } \\
(\mathrm{km})\end{array}$ & $\begin{array}{c}\text { Strike } \\
\left({ }^{\circ}\right)\end{array}$ & $\begin{array}{l}\text { Dip } \\
\left({ }^{\circ}\right)\end{array}$ & $\begin{array}{c}\text { Rake } \\
\left({ }^{\circ}\right)\end{array}$ & $\begin{array}{l}\text { Slip } \\
(\mathrm{m})\end{array}$ & $\begin{array}{c}\text { Length } \\
(\mathrm{km})\end{array}$ & $\begin{array}{l}\text { Width } \\
(\mathrm{km})\end{array}$ & $\begin{array}{c}\text { Misfit } \\
-\end{array}$ & - \\
\hline \multicolumn{13}{|l|}{ Existing studies } \\
\hline InSAR, Funning et al., (2005) & 7.7 & -17.899 & -65.164 & 7.40 & 7.0 & 79.0 & 171.0 & 1.1 & 14.5 & 15.0 & - & \\
\hline InSAR, Funning et al., (2005) (ds) & 8.44 & -17.893 & -65.177 & 7.30 & 7.0 & 79.0 & 171.0 & 0.6 & 24.0 & 18.0 & - & \\
\hline InSAR, Devlin et al., (2012) & - & -17.910 & -65.153 & $5.8 \pm 0.2$ & $1.0 \pm 1.0$ & $75.0 \pm 1.0$ & $179.0 \pm 1.0$ & - & $21.0 \pm 1.0$ & $8.0 \pm 1.0$ & - & \\
\hline Seismic, Devlin et al., (2012) & - & -17.860 & -65.539 & 11.0 & 358.0 & 84.0 & 179.0 & - & - & - & - & \\
\hline GCMT & 8.44 & -17.600 & -65.200 & 15.0 & 186.0 & 79.0 & -178.0 & - & - & - & - & \\
\hline \multicolumn{13}{|l|}{ This study } \\
\hline InSAR & 7.27 & -17.899 & -65.165 & 7.4 & 7.3 & 79.1 & 171.3 & 1.1 & 14.6 & 15.0 & 0.048 & \\
\hline LPS & 9.08 & -17.899 & -65.165 & 12.0 & 4.1 & 60.4 & 176.1 & 1.2 & 15.0 & 16.7 & 0.082 & \\
\hline LPB & 6.87 & -17.899 & -65.165 & 12.0 & 1.4 & 87.6 & 164.5 & 1.1 & 15.0 & 14.5 & 0.36 & \\
\hline LPS \& LPB & 7.7 & -17.899 & -65.165 & 12.0 & 4.6 & 90.0 & 180.0 & 1.2 & 15.0 & 14.5 & 0.193 & \\
\hline InSAR, LPS & 7.15 & -17.899 & -65.173 & 8.3 & 3.5 & 82.7 & 179.5 & 1.0 & 13.7 & 16.6 & 0.172 & \\
\hline InSAR, LPB & 4.64 & -17.911 & -65.162 & 7.23 & 7.5 & 75.2 & 161.1 & 0.87 & 11.8 & 15.0 & 0.156 & \\
\hline InSAR, LPS, LPB & 6.75 & -17.901 & -65.169 & 8.9 & 4.2 & 81.1 & 179.8 & 0.89 & 14.0 & 18.0 & 0.188 & \\
\hline
\end{tabular}

that a time window of $150 \mathrm{~s}$, instead of $200 \mathrm{~s}$, is used for the body waves as the data were too noisy beyond the $150 \mathrm{~s}$ cut-off.

Table 5 shows that the best-fitting model from the inversion using only body wave data exhibits a strike, dip and rake similar to published studies (Talebian et al. 2006; Rouhollahi et al. 2012), however, the moment is the lowest of all the source models listed $\left(M_{0}=4.64 \times 10^{18} \mathrm{Nm}\right)$. There is a clear trade-off between moment and dip in the resulting solution from the long-period surface 

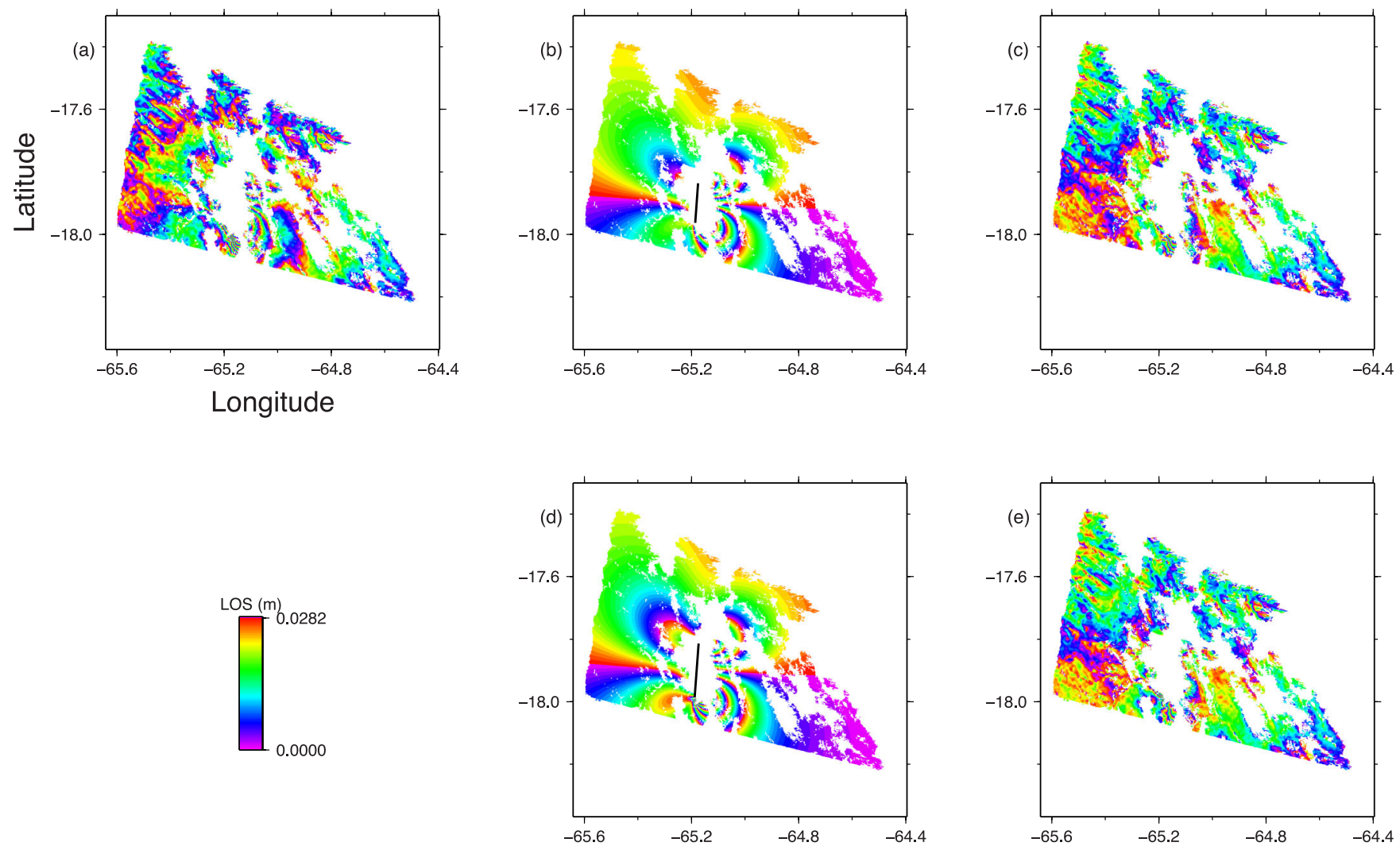

Figure 11. (a) Descending interferogram for the $M_{\mathrm{W}} 6.6$ Aiquile, Bolivia earthquake, calculated from two ERS-2 images (1996 April 11 and 1998 July 30 , Track 239) (b) Forward modelled interferogram using the joint inversion result listed in Table 4. The black line represents the updip projection of the top of the fault to the surface. (c) Residual between interferogram (a) and forward modelled results (b). (d) Shows the interferogram calculated using the joint inversion results, except the length has been increased to $19 \mathrm{~km}$, which is consistent with existing studies (Funning et al. 2005; Devlin et al. 2012), and the corresponding residual is shown in e).

wave inversion, with a very high moment and very shallow dip $\left(24.2^{\circ}\right)$, even shallower than the GCMT estimate of $44^{\circ}$. Separate inversions of the two interferograms result in source parameters which disagree regarding fault geometry, where models based on the ascending data favour a larger right lateral strike-slip component and a slightly higher moment ( $\sim 10$ per cent larger). The source model from the ascending interferogram shows a higher misfit to the data, which proved problematic when assigning weights to the data sets in the joint inversion. Thus instead of weighting according to the misfits from the individual inversions, a weight-search approach was taken. The weights were adjusted until the degradation in misfit for the geodetic and seismic data sets compared with those from separate inversions was relatively equal, providing an objective compromise between fitting all of the different data sets. After 50 inversion attempts the lowest and approximately equal degradations in misfits that could be achieved for both InSAR data sets meant an increase in misfit from 0.060 to 0.271 and 0.005 to 0.018 for the ascending and descending data, respectively. The misfit to the seismic data increased from 0.104 to 0.163 for LPS and 0.390 to 0.798 for LPB. This approach results in a source model which in general fits the seismic data well, particularly the LPS (Figs 16a-c). Overall the body wave data fit is good (Figs 16d-f), except for a few stations, notably where the fit in amplitude and phase to the SH arrival could be improved (e.g. for stations DGAR, PAB, TSUM, WRAB in Fig. 16f). The optimal source model from the joint inversion fits the observed deformation pattern well, for the descending interferogram. However, there are five fringes in the ascending residual (Fig. 15e), which is only one more fringe than those seen in the
InSAR-only result from Talebian et al. (2006). The trade-off plots in Fig. 17 clearly show the previously mentioned disagreement in source parameters between the two interferograms, and there is a slight trade-off in strike and moment evident in the seismic-only inversions (Fig. 17b). There is however, an improvement when the two interferograms are jointly inverted with the seismic data; the results (pink dots, Fig. 17) are much more tightly clustered, and the moment, dip and rake are particularly better constrained than in single-data type inversions.

\section{DISCUSSION}

The results from both synthetic tests and real data inversions will now be discussed in terms of the data used, fault geometry and mechanism, and centroid location, with particular reference to the effect of incorporating 3-D Earth structure in the modelling of seismic data.

The use of earthquake locations estimated using InSAR data along with a 3-D Earth structure model in seismic waveform simulations is an attempt at trying to resolve the issues surrounding the influence of the assumed Earth structure on source inversions. Results from synthetic tests using 1-D and 3-D Earth models show that long-period surface waves are more sensitive than long-period body waves to 3-D Earth structure (Tables 1 and 2, Fig. 5). The difference is particularly clear when assuming a 1-D Earth structure in the source inversions, with evident phase shifts in the Rayleigh waves (see Fig. 5a). Similar differences in waveforms from comparisons 
(a) LPS Z
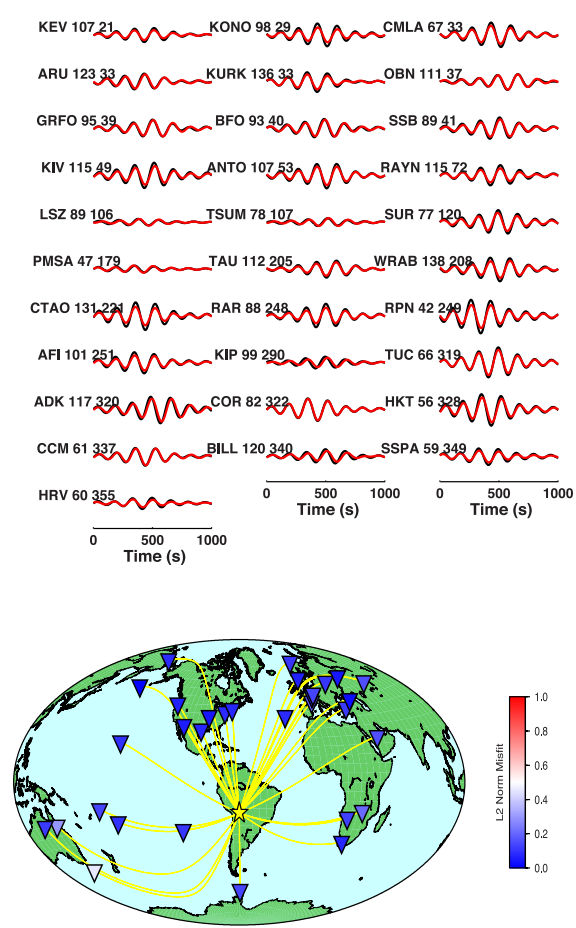

(d) LPB Z
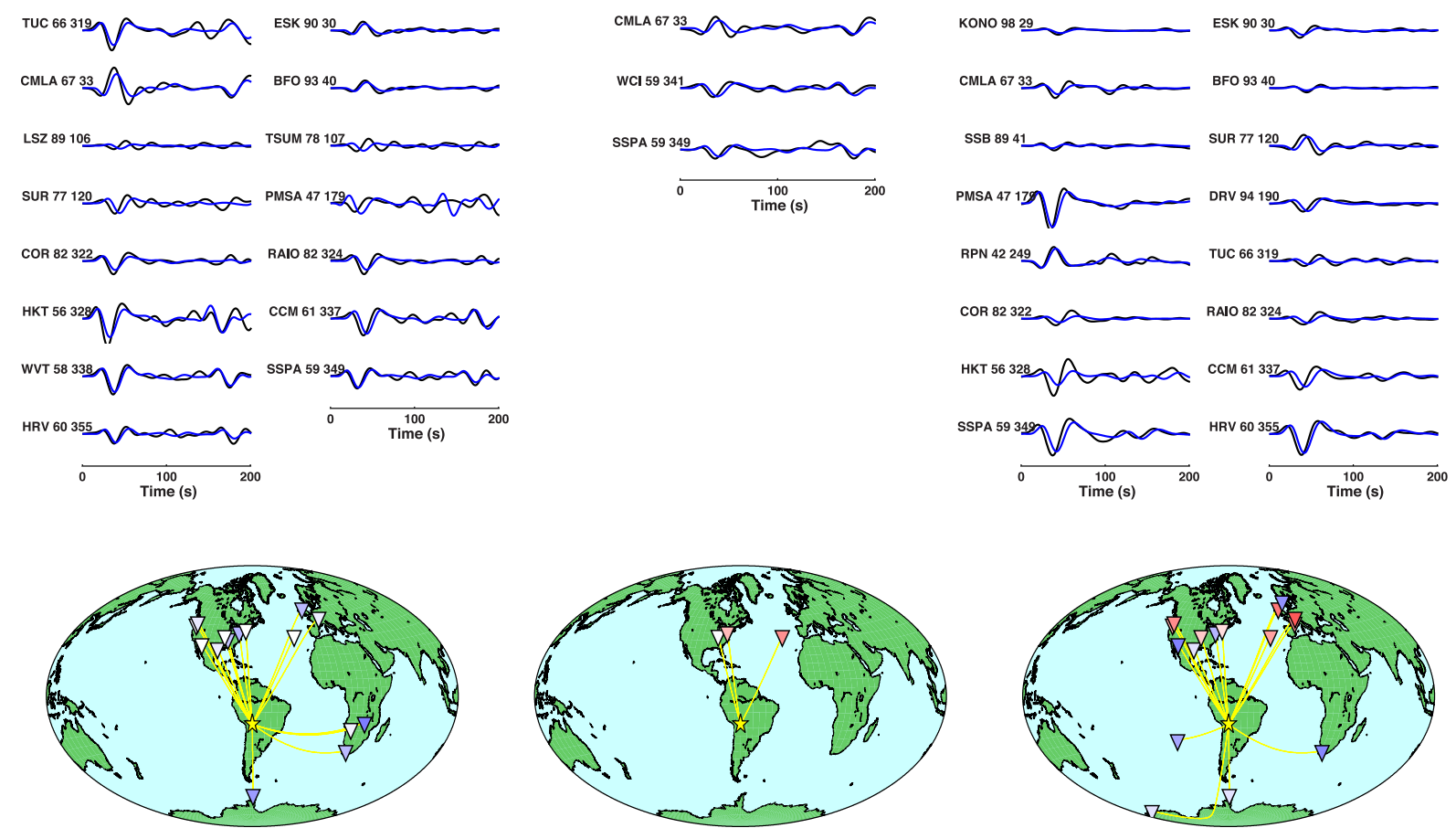

Figure 12. (a)-(c) Fit of joint inversion results for the $M_{\mathrm{w}} 6.6$ Aiquile earthquake (red) to the data (black), filtered for LPS where vertical (Z) transverse (T) and longitudinal (L) components are shown, respectively. The station distribution and its corresponding misfit to the data is shown underneath each component, and the format is the same as in Fig. 8. (d)-(f) Show the fit of the joint inversion results filtered for LPB (blue) to the data for the vertical, longitudinal, and transverse components, respectively. 


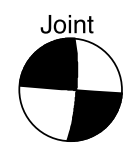

a)
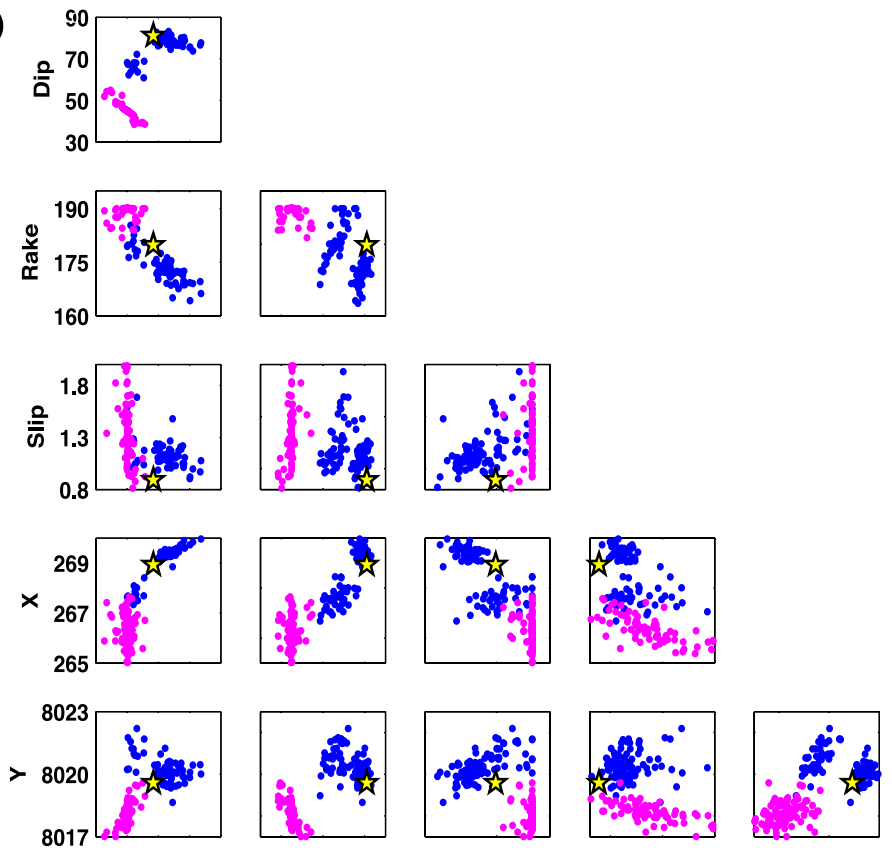

b)
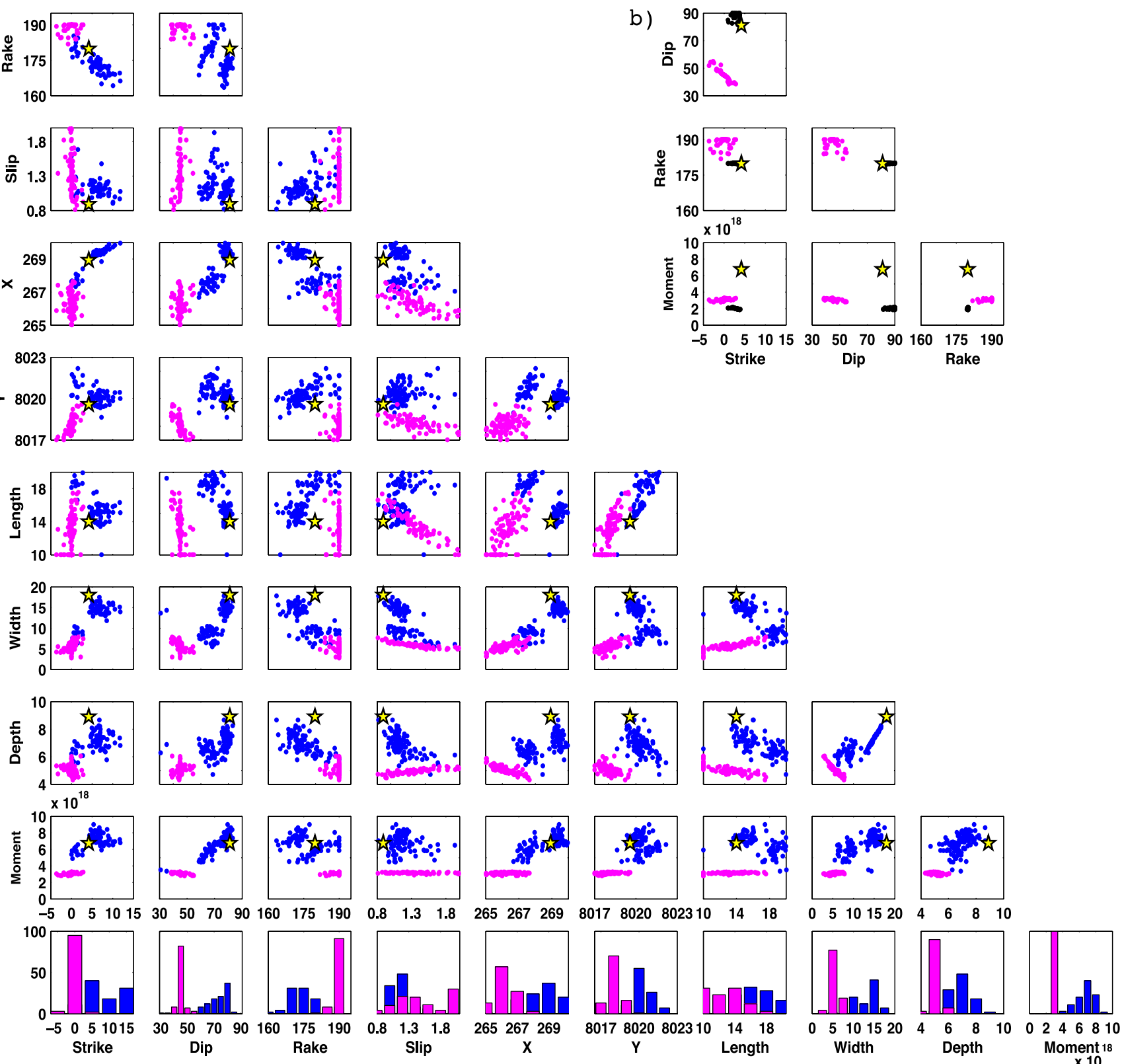

Figure 13. (a) Trade-off scatterplots for InSAR only inversion (blue) and joint source inversion (pink) for the $M_{\mathrm{W}}$ 6.6, Aiquile earthquake, with the focal mechanism from the joint source inversion shown in pink at the top. (b) Trade-off scatterplots for seismic only inversion. Format is same as in Fig. 4.

of wave propagation simulations for 1-D and 3-D earth models have been observed in other studies (e.g. Marquering et al. 1998; Furumura et al. 1999; Ferreira \& Woodhouse 2006, 2007).

The changes in seismic waveforms due to differences in Earth structure models influence the recovery of the resulting source parameters. In this study the fault dip angle is particularly poorly constrained in synthetic tests using the 1-D Earth model, PREM, with results from separate and joint inversions leading to steeper dips than the actual input model $\left(5-15^{\circ}\right.$ steeper). Ferreira \& Woodhouse (2006) found a similar trend when investigating the influence of the chosen Earth model on centroid moment tensor inversions, and Hayes \& Wald (2009) also observed steeper GCMT dips than the megathrust dips from their Slab1.0 model. Results from PREM surface wave inversions exhibit the steepest fault dips 

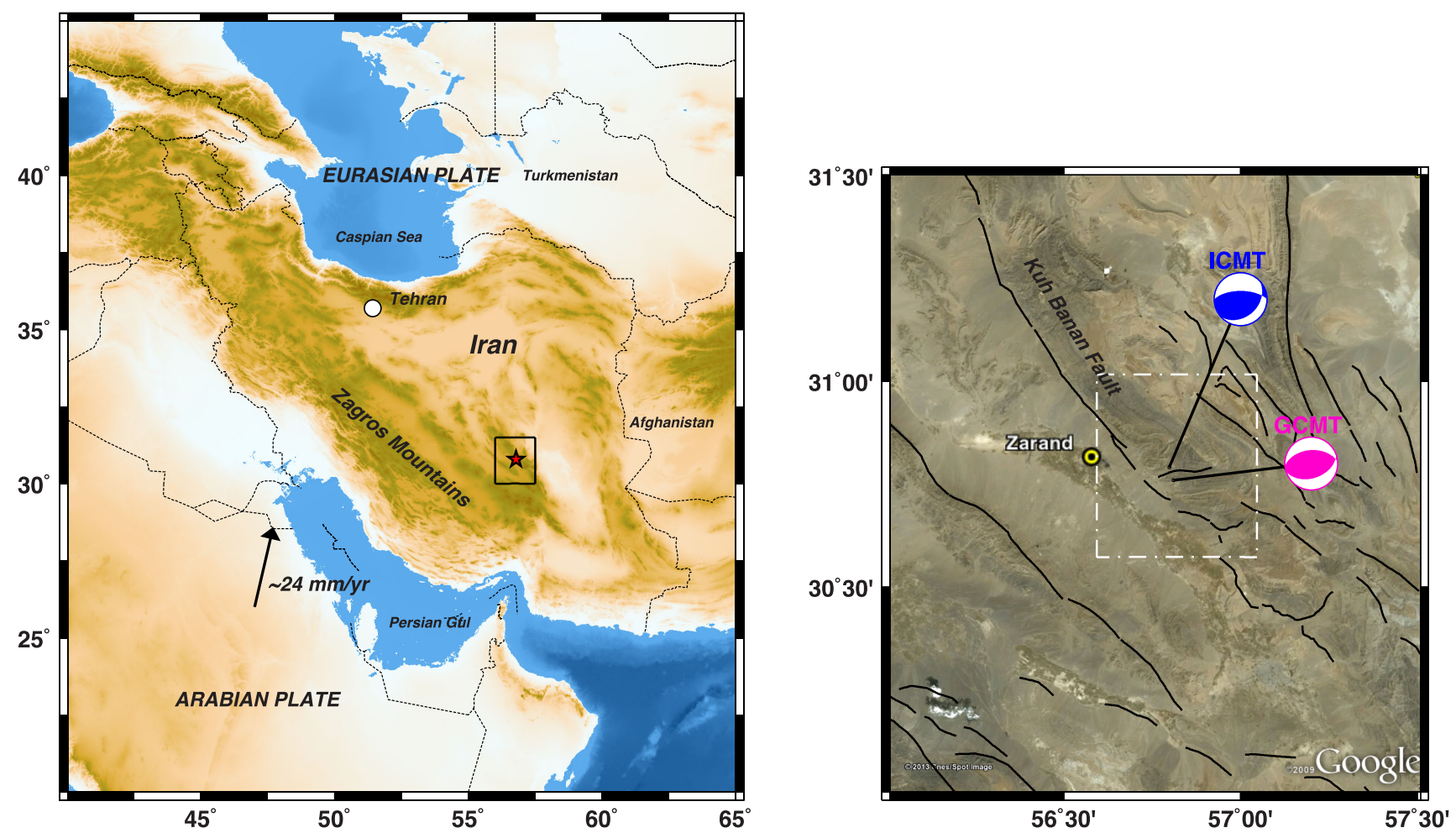

Figure 14. Tectonic setting for the $M_{\mathrm{W}} 6.5$ Zarand, Iran earthquake. Map on the left shows the overall regime due to the collision of the Arabian and Eurasian plates. The earthquake location is denoted by the red star and the black box refers to the figure on the right, where known faults in the region are shown in black, including the Kuh Banan fault zone; fault locations are from Walker et al., (2009). The white dashed box refers to the area covered by the two sets of InSAR data shown in Fig. 15, and the focal mechanisms from the GCMT catalogue and this study (ICMT) are shown in pink and blue, respectively.

and all other parameters are the furthest from the input solution, yet the surface wave solution leads to a relatively good fit to the data $\left(m^{2}=0.32\right)$. This suggests that errors in the Earth structure and in the retrieved source model compensate each other, leading to an overall good fit to the observed long-period surface waves.

The mislocation of events can be one result of this trade-off between source parameters and Earth structure, as is seen for the Eureka Valley and Aiquile earthquakes. The joint inversion results for these two case studies show that the previously reported 40 $50 \mathrm{~km}$ discrepancies in seismic and geodetic locations can be resolved. Using the locations determined with InSAR data in the modelling and the S40RTS and CRUST2.0 mantle and crustal models (different to the GCMT catalogue) lead to a good fit to the seismic data in both cases (Figs 8 and 12). Hence, the seismic data can be reconciled with InSAR-determined locations, including in complex regions such as the central Andes in Bolivia, where accurate earthquake locations and source models are especially important for further understanding the complicated regional tectonic regime. However, the use of the InSAR location to try and fit the seismic data could also be biasing other source parameters, due to additional trade-offs between location and Earth structure. This could also explain some of the variations in source parameters seen for the seismic-only inversions in comparison with the InSAR-only and joint inversion results, for example, the shallow dip estimates from the long-period surface wave inversions for all three case studies (Tables 3-5).

In particular, the body wave inversion results for Eureka Valley suggest a NE-SW strike $\left(210^{\circ}\right)$, which is in disagreement with the NW-SE estimates from a previous geodetic study (Massonnet \& Feigl 1995) and with separate InSAR and LPS inversions in this study. If this strike value is substituted into the joint inversion results the fit to the interferogram is significantly deteriorated (Figs $7 \mathrm{~d}$ and e). This strongly suggests that for this event the fault strike value obtained from body wave inversions is inconsistent with observations, especially when considering the deformation pattern for this event, which provides a strong visual constraint on the strike (Fig. 7a). Furthermore, the strike obtained from our body wave inversions agrees well with estimates from seismic studies that assume a 1-D velocity structure (Ichinose et al. 2003), whereas an aftershock relocation study using a 3-D velocity model obtains a fault plane with a strike of $165^{\circ}$ that is in better agreement with the LPS inversion in this study, which also employs a 3-D Earth structure model. Therefore, Earth structure errors at a small scale $(<100 \mathrm{~km})$ could be further amplifying this trade-off between location and structure, as the shorter period body waves are more sensitive to small-scale heterogeneities than the longer period surface waves. The use of a higher resolution Earth model (if it were available) could perhaps improve the body wave modelling.

Alternatively, the poorer fit of the body waves in comparison with the surface waves (Fig. 8) could be the result of the assumption that a point source or planar fault is sufficient to explain the seismic and geodetic data, respectively. Existing studies and the results reported here for the Eureka Valley earthquake show a wide variation in fault geometry, which might be due to the complex nature of the event. Asad et al. (1999) suggest that the fault could be slightly concave, based on the curvature of the aftershock locations. If this is the case then the shorter period body waves are likely to be more sensitive to this complexity then longer period surface waves, hence the poorer fit of the joint inversion result to these waveforms (Figs 8c and d).

Existing seismic source inversion techniques take into account the effect of errors in the chosen 1-D or 3-D Earth model on the inversion result by aligning the waveforms in time or by applying 
(a)

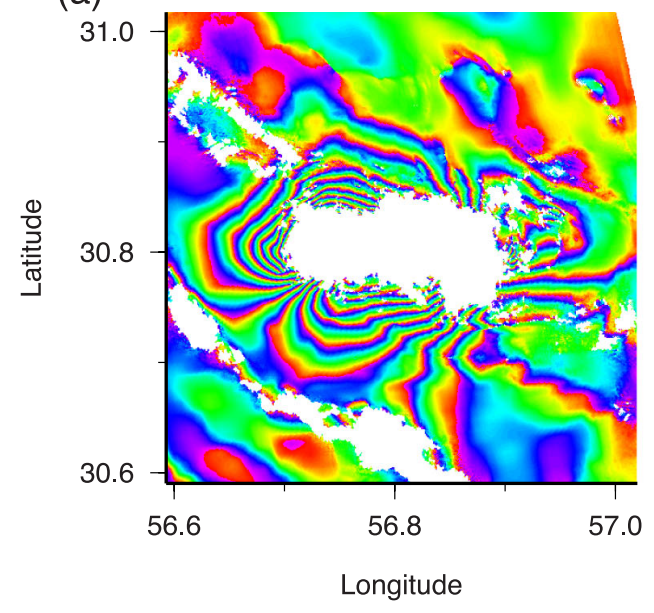

(c)

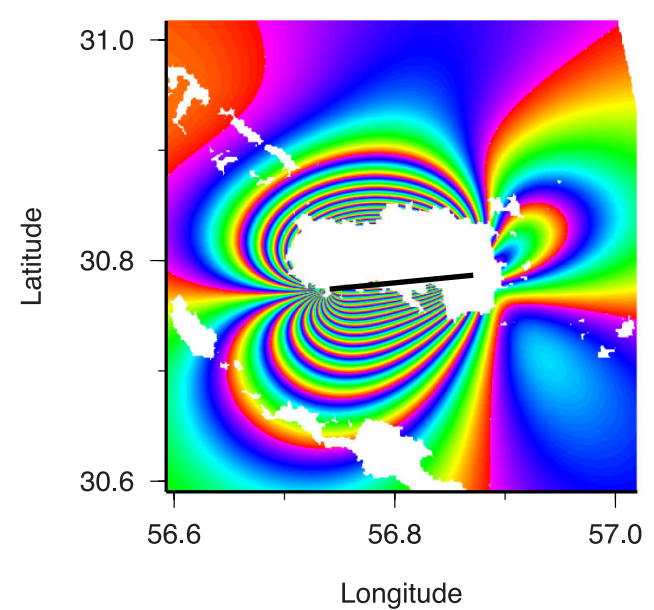

(e)

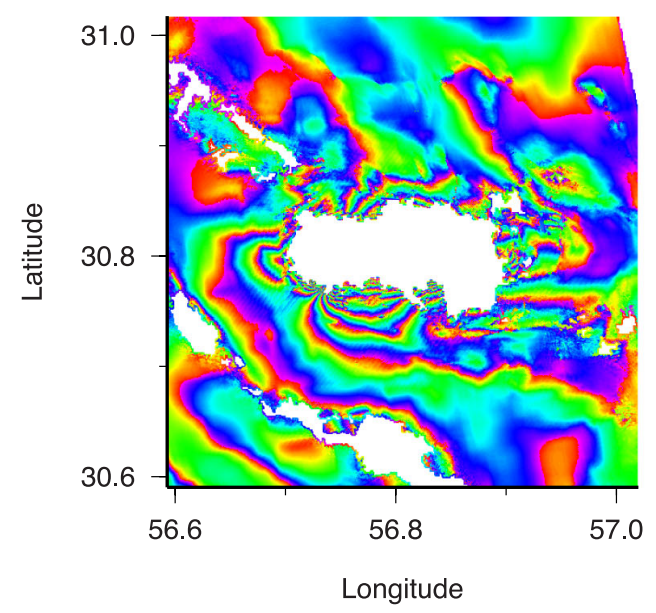

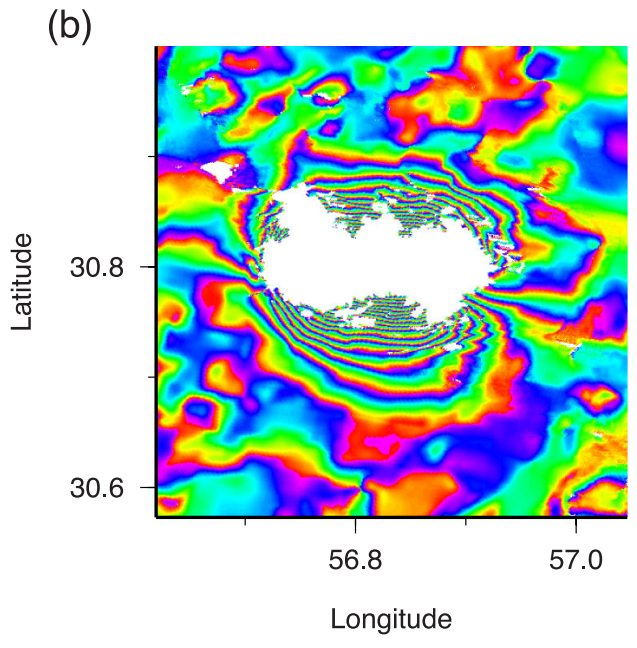

(d)

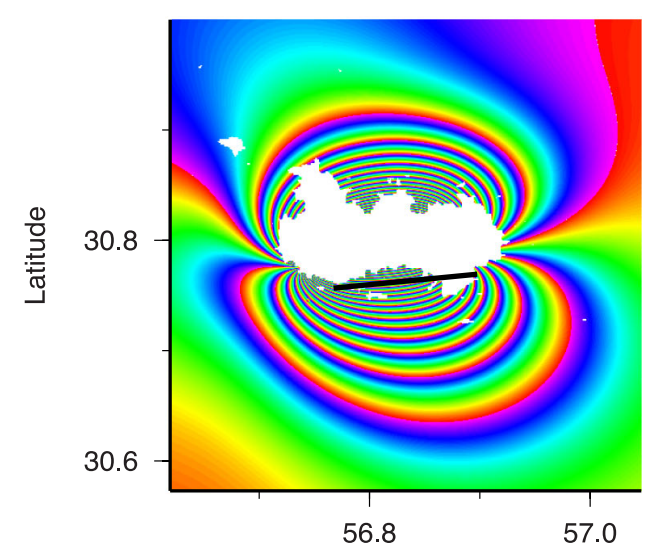

Longitude

(f)

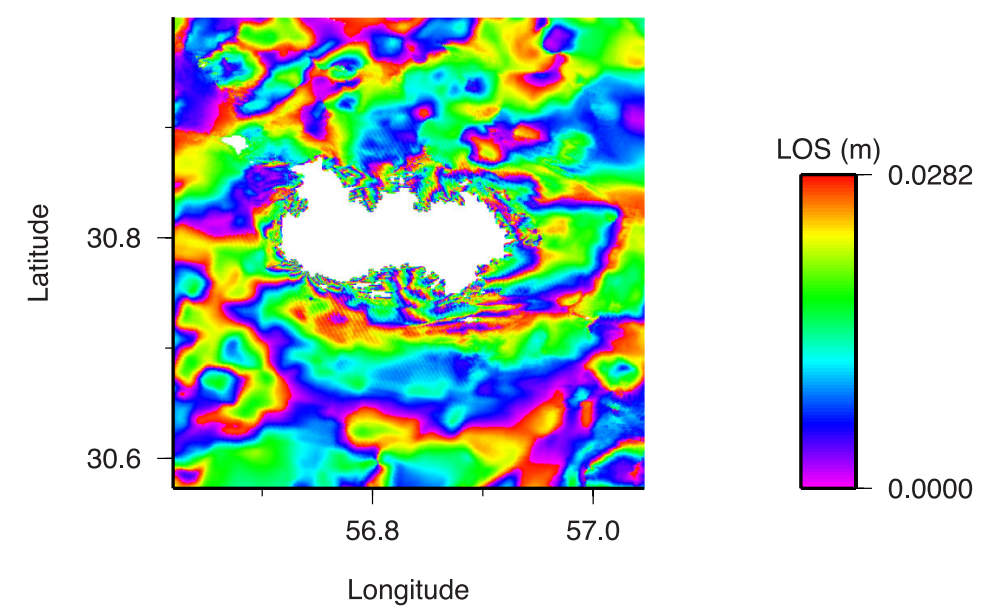

Figure 15. Fit of joint inversion results for the $M_{\mathrm{w}} 6.5$ Zarand earthquake. (a) Ascending interferogram calculated using two images from 2004 September 19 and 2005 March 13, taken on track 285. (b) Descending data calculated using images from 2005 February 17 and 2005 March 24 on track 435 . The second row (c) and (d) are synthetic ascending and descending interferograms, respectively, forward modelled using the joint source inversion result. The black line refers to the location of the top of the fault plane. (e)-(f) are the residuals for the ascending and descending data and results, respectively. 
(a) LPS Z

$$
\text { TUC } 116 \text { 348 }
$$

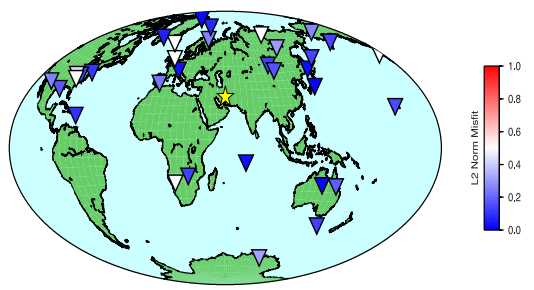

(d) LPB Z
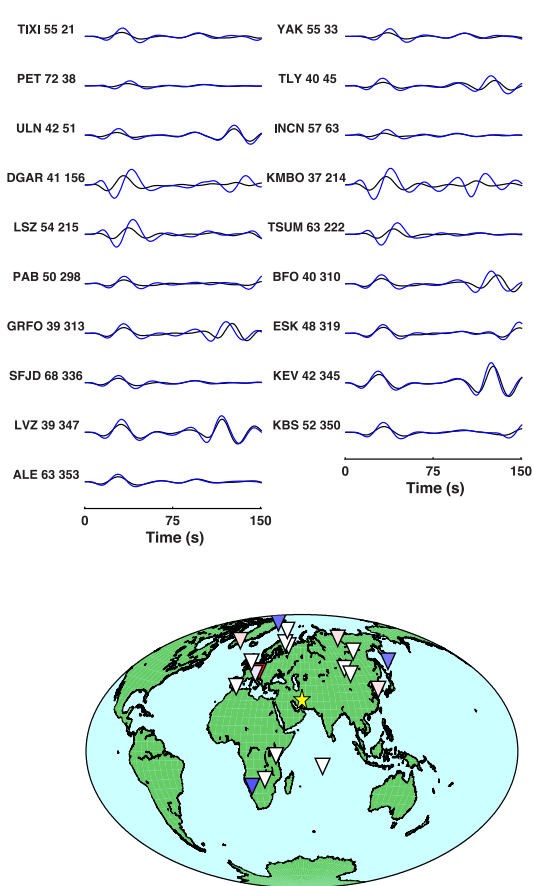

(b) LPS L

$$
\text { PAB } 50 \text { 2998 } 4045
$$

(c) LPS T

$$
\text { LSZ 54215 }
$$
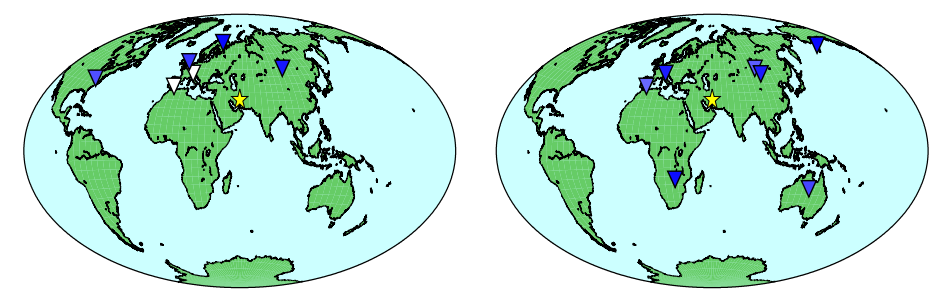

(e) LPB L

(f) LPB T
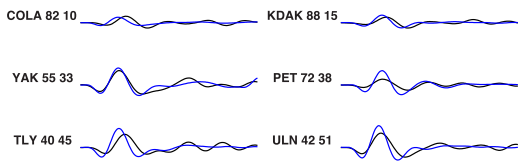

MAJO 6660 GUM08179

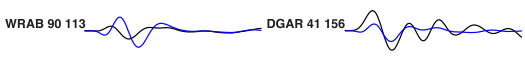

LSZ $54215 \sim 2$ TSUM 63 222
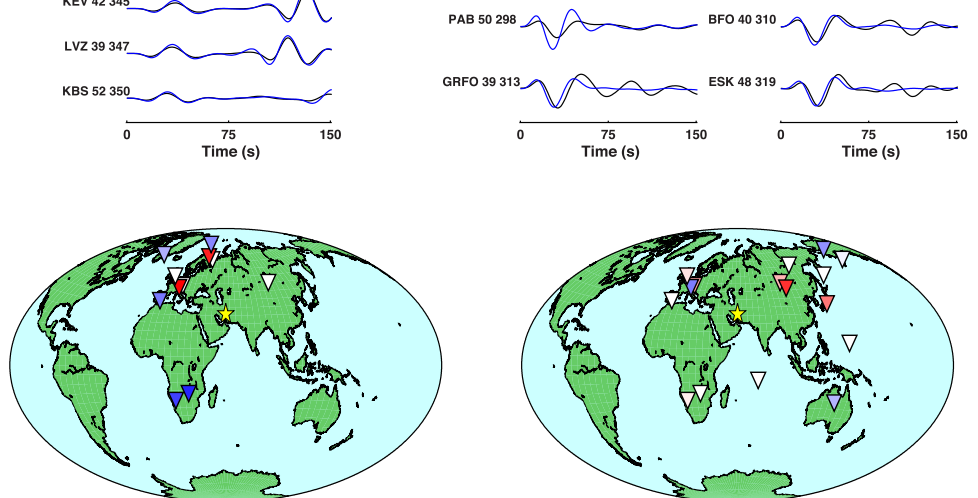

Figure 16. (a)-(c) Fit of joint inversion results for the $M_{\mathrm{W}} 6.5$ Zarand earthquake (red) to the data (black), filtered for LPS where vertical (Z) transverse (T) and longitudinal (L) components are shown, respectively. The station distribution and its corresponding misfit to the data are shown in the maps underneath, and the format is the same as in Figs 8(d)-(f) The fit of the joint inversion results filtered for LPB to the data for the vertical, longitudinal and transverse components, respectively.

phase velocity corrections (e.g. GCMT, Dziewonski et al. 1992). The use of InSAR-determined source parameters, in particular location, and of highly accurate seismic forward modelling taking into account 3-D Earth structure may ultimately provide an independent means of testing these approaches. This is beyond the scope of this study and will be the subject of future work.

Overall though, the synthetic tests in the presence of noise carried out in this study clearly show that the joint inversion technique 
Table 5. Summary of source inversion results and existing studies for the $M_{w} 6.5$ Zarand earthquake. Format is same as in Table 3 .

\begin{tabular}{|c|c|c|c|c|c|c|c|c|c|c|c|}
\hline Study & Mo $\left(x 10^{18} \mathrm{Nm}\right)$ & Lat ${ }^{\circ}()$ & Lon ${ }^{(0)}$ & Depth $(\mathrm{km})$ & Strike ${ }^{(\circ)}$ & $\operatorname{Dip}^{(0)}$ & Rake $^{(\circ)}$ & Slip $(\mathrm{m})$ & Length $(\mathrm{km})$ & Width (km) & $\mathrm{m}^{2}$ \\
\hline Bodywaves, Talebian et al., (2006) & 4.9 & 56.736 & 30.774 & 7.93 & 270 & 60 & 104 & 0.8 & - & - & - \\
\hline InSAR - Talebian et al., (2006) & 6.7 & - & - & 4.8 & 266 & 67 & 105 & 1.6 & 12.6 & 10.4 & \\
\hline Strong motion - Rouhollahi et al. (2012) & 7.0 & - & - & - & 260.0 & 60.0 & 104.0 & - & 18.0 & 14.0 & - \\
\hline GCMT & 5.2 & 56.800 & 30.760 & 12.0 & 266.0 & 46.0 & 124.0 & - & - & - & - \\
\hline This study & & & & & & & & & & & \\
\hline InSAR & 6.37 & 56.797 & 30.803 & 4.6 & 266.1 & 63.7 & 104.1 & 1.92 & 13.1 & 8.5 & 0.090 \\
\hline $\operatorname{InSAR}_{a s c}$ & 7.79 & 56.793 & 30.805 & 4.6 & 265.8 & 62.7 & 112.5 & 2.48 & 13.9 & 7.6 & 0.060 \\
\hline $\operatorname{InSAR}_{d s c}$ & 6.93 & 56.806 & 30.800 & 4.1 & 273.3 & 64.3 & 97.4 & 1.97 & 13.3 & 8.8 & 0.005 \\
\hline LPS & 8.52 & 56.797 & 30.803 & 12.0 & 284.2 & 24.2 & 136.2 & 1.1 & 13.0 & 20.75 & 0.100 \\
\hline LPB & 4.64 & 56.797 & 30.803 & 12.0 & 272.3 & 55.7 & 104.3 & 1.15 & 13.0 & 10.3 & 0.390 \\
\hline LPS \& LPB & 5.23 & 56.797 & 30.803 & 12.0 & 276.7 & 55.8 & 113.2 & 1.30 & 13.0 & 10.3 & 0.238 \\
\hline InSAR \& LPS & 6.37 & 56.805 & 30.800 & 4.4 & 268.0 & 65.0 & 98.8 & 2.14 & 12.9 & 7.7 & 0.037 \\
\hline InSAR \& LPB & 6.94 & 56.806 & 30.799 & 4.1 & 267.7 & 62.5 & 93.0 & 2.16 & 12.8 & 8.3 & 0.042 \\
\hline InSAR, LPS \& LPB & 6.58 & 56.804 & 30.799 & 4.3 & 263.8 & 64.4 & 94.3 & 1.84 & 12.5 & 9.5 & 0.073 \\
\hline
\end{tabular}

reduces the level of trade-offs within model solutions. Moreover, for all three case studies, we find that the source parameters, particularly fault strike, dip and rake, are more robustly constrained in joint inversions using InSAR and seismic data than in separate data inversions (Figs 9, 13 and 17), and that both data sets are fit reasonably well. However, when considering the results for real earthquakes, the fit to the InSAR data for the Aiquile and Zarand events could be improved. The few fringes of displacement in the residual interferogram for Aiquile (Fig. 11c) could be due to the underestimation of the fault length in the joint inversion, $14 \mathrm{~km}$ in comparison with the $24 \mathrm{~km}$ and $21 \mathrm{~km}$ reported by Funning et al. (2005) and Devlin et al. (2012), respectively. If a length of $19 \mathrm{~km}$ is substituted into the joint inversion result then a residual interferogram similar to that seen in Funning et al. (2005) is obtained (see Fig. 11d) and the number of residual fringes are reduced (Fig. 11e). Therefore the length is likely underestimated, and this could be due to the trade-offs between length, width and slip that are not resolved in the joint inversion (Fig. 13a), partly because the InSAR data in this case only provide a weak constraint on fault length given the incoherence present in the epicentral area. Furthermore, the addition of seismic data may not fully resolve these trade-offs because even though it is able to constrain the moment, the period of the data used provides little constraint on the length, as the earthquake is a point source with respect to the wavelength.

For the Zarand earthquake, separate inversions of the ascending and descending InSAR data led to source parameters with considerable discrepancies, with fault rake exhibiting the largest difference. This type of issue has previously been reported in inversions with synthetic data (e.g. Lohman et al. 2002), and it is widely acknowledged that data from both ascending and descending tracks are needed to constrain the rake as the displacements are measured from more than one look direction (e.g. Wright et al. 2003). Moreover, the ascending data were acquired at a shallower LOS angle to the descending data $\left(41^{\circ}\right.$ compared with $\left.23^{\circ}\right)$, which means they are more sensitive to horizontal motions. Yet, because the deformation patterns for both interferograms are very similar (Figs 15a and b), it suggests that vertical motions were the predominant displacement (Talebian et al. 2006). This could partly explain the fault geometry discrepancies between the ascending and descending inversion results, and also the higher misfit associated with the source model based on the ascending data. Consequently, this led to the downweighting of the ascending data in the joint inversion with respect to the descending data. However, this initial approach based on misfits from separate inversions resulted in a model with an unacceptable fit to the ascending data. This motivated us to carry out a search for the weights leading to a minimum degradation of the misfits of the InSAR and seismic data sets compared to the misfit values obtained from inversions of the separate data sets. The resulting source model from the joint inversion fits the descending InSAR data and long period body and surface waves well (Figs 15 and 16); a few fringes remain in the ascending residual (Fig. 15e) but even in the InSAR only inversion the ascending data is still not fully explained (see Fig. S5 in the supplementary materials). Talebian et al. (2006) encounter a similar issue and suggest that a kink in the fault could better explain the data, but is not consistent with their field observations. Alternatively a fault which has a change in dip at depth, or the incorporation of distributed slip to the modelling might improve the fit to the observed deformation pattern. In addition, a more complicated misfit function could be adopted, such as a combination of different misfit approaches for each type of data set ( Ji et al. 2002), weighting according to the noise in the data (Sudhaus \& Jónsson 2009), or weighting individual data points rather than the whole data set (e.g. seismic data can be weighted according to the azimuthal distribution of stations, Vallée et al. 2011). This will be the subject of future work.

\section{CONCLUSIONS}

A new joint earthquake source inversion technique is presented, which uses InSAR and long-period teleseismic data and takes into 


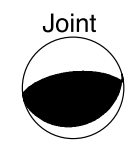

a)
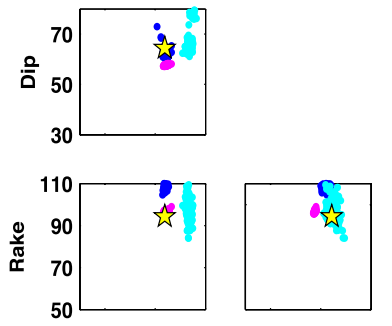

b)
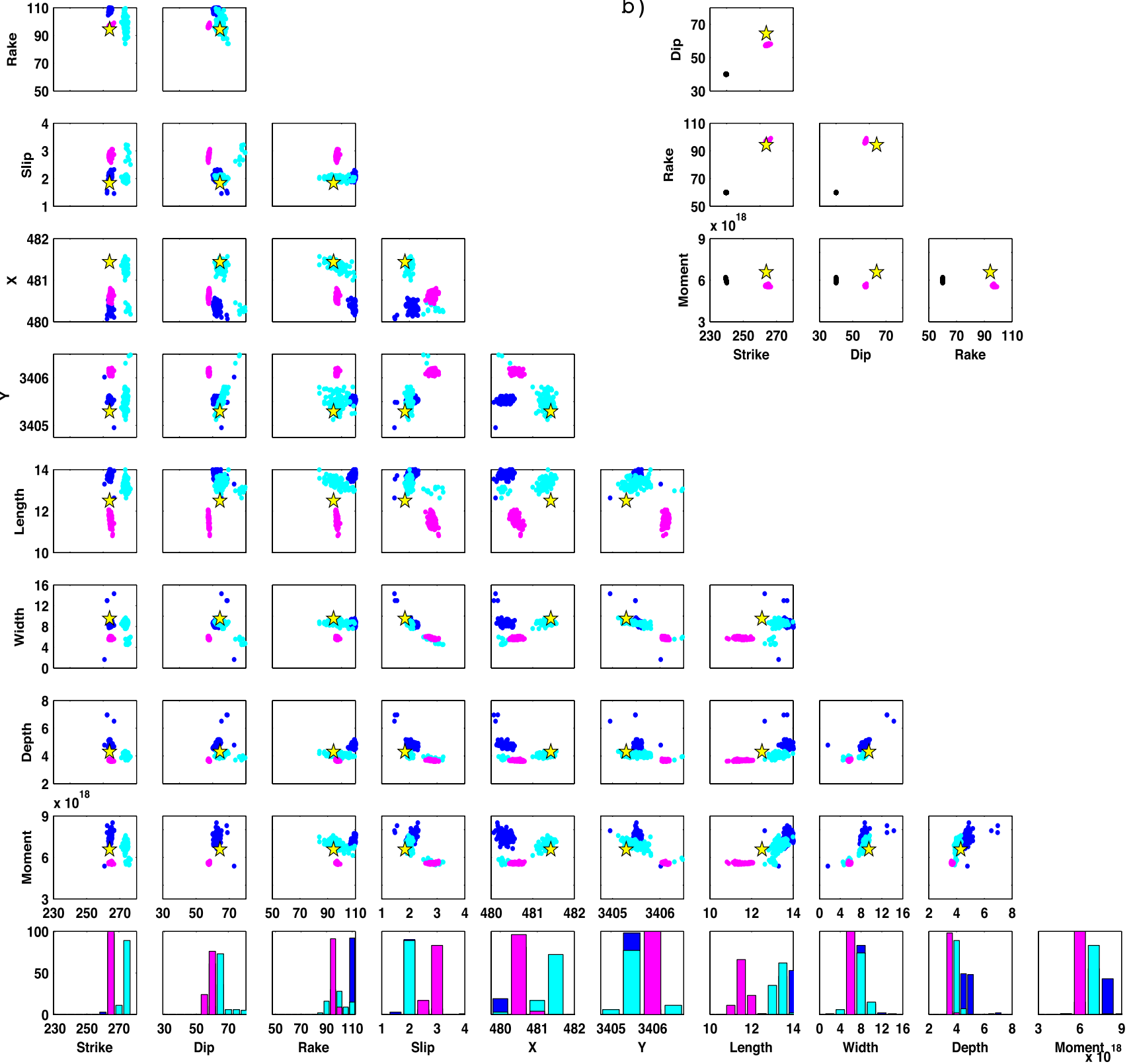

Figure 17. (a) Trade-off scatterplots for joint inversion results (pink) and InSAR for the $M_{\mathrm{W}} 6.5$ Zarand earthquake, where separate inversions were carried out using the ascending (cyan) and descending (blue) data and the focal mechanism is shown in pink at the top, and the corresponding source parameters are denoted by the black stars. (b) Trade-off scatterplots for the seismic-only (black) and joint inversions. The format is the same as in Fig. 4.

account the effects of 3-D Earth structure when modelling the seismic data. Synthetic tests in the presence of data noise and using 1-D and 3-D Earth models highlight the improvement in fault geometry and moment determinations that can be achieved by com- bining InSAR and seismic data, particularly when using a 3-D Earth model.

Using the InSAR location and assuming a 3-D Earth structure to calculate the excitation kernels demonstrates that the two data sets 
can be reconciled and overall a good fit to both data sets can be achieved. Trade-offs between fault geometry and moment are reduced in the joint inversions when compared with separate inversion results. When considering real events, in some cases where there are discrepancies between the separate long-period surface and body wave inversions that are not fully resolved in the joint inversion, this could partly be explained by unmodelled lateral heterogeneities in the assumed Earth model or by complexities in the source process. For example, the body wave inversion results for the Eureka Valley earthquake suggest that improved modelling of seismic waves at these considered periods could require the incorporation of smaller scale heterogeneities in current earth models. Consequently, higher resolution $(\leq 100 \mathrm{~km})$ global mantle and crustal models in the future would be beneficial for teleseismic source studies. Overall this technique illustrates the existing potential to rapidly incorporate the effects of 3-D Earth structure and combine the strengths of InSAR and seismic data to determine robust earthquake source models.

\section{ACKNOWLEDGEMENTS}

We are grateful to both the reviewers for their comments, which helped improve the quality of the manuscript. The research presented in this paper was carried out on the High Performance Computing Cluster supported by the Research and Specialist Computing Support service at the University of East Anglia and at the U.K. NERC-EPSRC National Supercomputing facilities HECToR. We gratefully acknowledge the availability of global seismograms from the FDSN global network and the IRIS Data Centre. JW was funded by NERC and is grateful for initial support from a grant by the U.K. Royal Astronomical Society (RAS). AMGF is grateful for the support from the European Commissions Initial Training Network project QUEST (contract FP7PEOPLEITN2008238007). The figures were produced using the GMT package (Wessel \& Smith 1991).

\section{REFERENCES}

Aki, K. \& Richards, P., 2002. Quantitative Seismology, 2nd edn, University Science Books.

Allmendinger, R., Smalley, R., Bevis, M., Caprio, H. \& Brooks, B., 2005. Bending the Bolivian orocline in real time, Geology, 33, 905-908.

Ambraseys, N. \& Jackson, J. A., 1998. Faulting associated with historical and recent earthquakes in the Eastern Mediterranean region, Geophys. $J$. Int., 133, 390-406.

Asad, A., Pullammanappallil, S., Anooshehppor, A. \& Louie, J., 1999. Inversion of travel-time data for earthquake locations and three-dimensional velocity structure in the Eureka Valley area, Eastern California, Bull. seism. Soc. Am., 89(3), 796-810.

Astiz, L., Shearer, P. \& Agnew, D., 2000. Precise relocations and stress change calculations for the Upland earthquake in sequence in southern California, J. geophys. Res., 105(B2), 2937-2953.

Atwater, T., 1970. Implications of plate tectonics for the Cenozoic tectonic evolution of Western North America, Geol. soc. Am. Bull., 81, 3513-3536.

Barke, R., Lamb, S. \& MacNiocaill, C., 2007. Late Cenozoic bending of the Bolivian Andes: new paleomagnetic and kinematic constraints, $J$. geophys. Res., 112, B01101, doi:10.1029/2006JB004372.

Bassin, C., Laske, G. \& Masters, G., 2000. The current limits of resolution for surface wave tomography in North America, EOS, Trans. Am. geophys. Un., 81, F897.

Berberian, M. et al., 2001. The 1998 March 14 Fandoqa earthquake (Mw 6.6) in Kerman province, southeast Iran: re-rupture of the 1981 Sirch earthquake fault, triggering of slip on adjacent thrusts and the active tectonics of the Gowk fault zone, Geophys. J. Int., 146, 371-398.

Brooks, B. et al., 2011. Orogenic-wedge deformation and potential for great earthquakes in the central Andean back arc, Nat. Geosci., 4, 380-383.
Clarke, P., Paradissis, D., Briole, P., England, P., Parsons, B., Billiris, H., Veis, G. \& Ruegg, J.-C., 1997. Geodetic investigation of the 13 May 1995 Kozani - Grevena (Greece) earthquake, Geophys. Res. Lett., 24(6), 707-710.

Covellone, B. \& Savage, B., 2012. A quantitative comparison between 1D and 3D source inversion methodologies: application to the Middle East, Bull. seism. Soc. Am., 102(5), 2189-2199.

Delouis, B., Giardini, D., Lundgren, P. \& Salichon, J., 2002. Joint Inversion of InSAR, GPS, Teleseismic, and strong-motion data for the spatial and temporal distribution of earthquake slip: application to the 1999 Izmit Mainshock, Bull. seism. Soc. Am., 92, 278-299.

Devlin, S., Isacks, B., Pritchard, M., Barnhart, W. \& Lohman, R.B., 2012. Depths and focal mechanisms of crustal earthquakes in the central Andes determined from teleseismic wavform analysis and InSAR, Tectonics, 31, TC2002, doi:10.1029/2011TC002914.

Dewey, J. \& Lamb, S.H., 1992. Active tectonics of the Andes, Tectonophysics, 205, 79-95.

Dziewonski, A.M. \& Anderson, D., 1981. Preliminary reference Earth model, Phys. Earth planet. Inter., 25, 297-356.

Dziewonski, A.M., Chou, T.A. \& Woodhouse, J.H., 1981. Determination of earthquake source parameters from waveform data for studies of global and regional seismicity, J. geophys. Res., 86, 2825-2852.

Dziewonski, A.M., Ekstrom, G. \& Salganik, M.P., 1992. Centroid-moment tensor solutions for July-September 1991, Phys. Earth planet. Int., 72, $1-11$.

Ekström, G., Nettles, M. \& Dziewonski, A.M., 2012. The global CMT project 2004-2010: Centroid-moment tensors for 13,017 earthquakes, Phys. Earth planet. Int., 200-201, 1-9.

Enescu, B., Aoi, S., Toda, S., Suzuki, W., Obara, K., Shiomi, K. \& Takeda, T., 2012. Stress perturbations and seismic response associated with the 2011 M9.0 Tohoku-oki earthquake in and around the Tokai seismic gap, central Japan, Geophys. Res. Lett., 39, L00G28, doi:10.1029/2012GL051839.

Farr, T. et al., 2007. The Shuttle Radar Topography Mission, Rev. Geophys., 45, RG2004, doi:10.1029/2005RG000183.

Ferreira, A. \& Woodhouse, J.H., 2006. Long-period seismic source inversions using global tomographic models, Geophys. J. Int., 166, 1178-1192.

Ferreira, A. \& Woodhouse, J.H., 2007. Source, path and receiver effects on seismic surface waves, Geophys. J. Int., 168, 109-132.

Ferreira, A., Weston, J. \& Funning, G.J., 2011. Global compilation of interferometric synthetic aperture radar earthquake source models: 2. Effects of 3D earth structure, J. geophys. Res., 116, B08409, doi:10.1029/2010JB008132.

Funning, G.J., 2005. Source parameters of large shallow earthquakes in the Alpine-Himalayan belt from InSAR and waveform modelling, $P h D$ thesis, Faculty of Physical Sciences, University of Oxford.

Funning, G.J., Barker, R.M.D., Lamb, S.H., Minaya, E., Parsons, B. \& Wright, T.J., 2005. The 1998 Aiquile, Bolivia earthquake: a seismically active fault revealed with InSAR, Earth planet. Sci. Lett., 232, 39-49.

Furumura, M., Kennett, B.L.N. \& Furumura, T., 1999. Seismic wavefield calculation for laterally heterogeneous earth models-II. The influence of upper mantle heterogeneity, Geophys. J. Int., 139, 623-644.

Gilbert, F., 1976. The representation of seismic displacements in terms of travelling waves, Geophys. J. R. astr. Soc., 44, 275-280.

Gilbert, F. \& Dziewonski, A.M., 1975. An application of normal mode theory to the retrieval of structural parameters and source mechanisms from seismic spectra, Phil. Trans. R. Soc. Lond., 278(1280), 187-269.

Goldstein, R. \& Werner, C., 1998. Radar interferogram filtering for geophysical applications, Geophys. Res. Lett., 25, 4035-4038.

Goldstein, R.M., Zebker, H. \& Werner, C., 1988. Satellite radar interferometry: two-dimensional phase unwrapping, Radio Science, 23, 713-720.

Graves, R. \& Wald, D., 2001. Resolution analysis of finite fault source inversion using one- and three-dimensional Green's functions 1. Strong motions, J. geophys. Res., 106(B5), 8745-8766.

Hanssen, R., 2001. Radar Interferometry: Data Interpretation and Error Analysis, Kluwer.

Hayes, G. \& Wald, D., 2009. Developing framework to constrain the geometry of the seismic rupture plane on subduction interfaces a priori-a probablistic approach, Geophys. J. Int., 176, 951-964. 
Hearn, E.H. \& Bürgmann, R., 2005. The effect of elastic layering on inversions of GPS data for coseismic slip and resulting stress changes: strike-slip earthquakes, Bull. seismol. Soc. Am., 95, 1637-1653.

Hernandez, B., Cotton, F. \& Campillo, M., 1999. Contribution of radar interferometry to a two-step inversion of the kinematic process of the Landers earthquake, J. geophys. Res., 104, 13 083-13 099.

Hjörleifsdóttir, V. \& Ekström, G., 2009. Effects of three-dimensional Earth structure on CMT earthquake parameters, Phys. Earth planet. Inter., 179, 178-190.

Ichinose, G., Anderson, G., Smith, K. \& Zeng, Y., 2003. Source parameters of eastern California and western Nevada earthquakes from regional moment tensor inversion, Bull. seism. Soc. Am., 93(1), 61-84.

Isacks, B., 1988. Uplift of the central Andean plateau and bending of the Bolivian orocline, J. geophys. Res., 93, 3211-3231.

Jackson, J. \& McKenzie, D., 1984. Active tectonics of the Alpine-Himalayan Belt between western Turkey and Pakistan, Geophys. J. R. astr. Soc., 77, 185-264.

Ji, C., Wald, D. \& Helmberger, D., 2002. Source description of the 1999 Hector Mine, California, earthquake, Part I: wavelet domain inversion theory and resolution analysis, Bull. seism. Soc. Am., 92(4), 1192-1207.

Jonsson, S., Zebker, H., Segall, P. \& Amelung, F., 2002. Fault slip distribution of the $1999 \mathrm{Mw} 7.1$ Hector Mine, California, earthquake, estimated from satellite radar and GPS measurements, Bull. seism. Soc. Am., 92, 13771389.

Kanamori, H. \& Given, J., 1981. USe of long-period surface wabes for rapid determination of earthquake source parameters, Phys. Earth planet. Inter., 27, 8-31.

Kaverina, A., Dreger, D. \& Price, E., 2002. The combined inversion of seismic and geodetic data for the source process of the 16 October 1999 Mw 7.1 Hector Mine, California, earthquake, Bull. seism. Soc. Am., 92(4), 1266-1280.

King, G. C.P., Stein, R. \& Lin, J., 1994. Static stress changes and the triggering of earthquakes, Bull. seism. Soc. Am., 84, 935-953.

Komatitsch, D. \& Tromp, J., 1999. Introduction to the spectral element method for three-dimensional seismic wave propagation, Geophys. J. Int., 139, 806-822.

Komatitsch, D. \& Tromp, J., 2010. SPECFEM 3D GLOBE User Manual Version 5.1

Kubo, A., Fukuyama, E., Kawai, H. \& Nonomura, K., 2002. NIED seismic moment tensor catalogue for regional earthquakes around Japan: quality test and application, Tectonophysics, 356, 23-48.

Lamb, S., 2000. Active deformation in the Bolivian Andes, South America, J. geophys. Res., 105(B11), 25 627-25653.

Lohman, R.B. \& Simons, M., 2005. Locations of selected small earthquakes in the Zagros mountains, Geochem., Geophys., Geosyst., 6, Q03001, doi: 10.1029/2004GC000849.

Lohman, R.B., Simons, M. \& Savage, B., 2002. Location and mechanism of the Little Skull Mountain earthquake as constrained by satellite radar interferometry and seismic waveform modelling, J geophys. Res., 107(B6), 2118, doi:10.1029/2001JB000627.

Mai, M., 2004. SRCMOD: a database of finite-source rupture models. Available at: www.seismo.ethz.ch/srcmod (last accessed May 2011).

Marquering, H., Nolet, G. \& Dahlen, F.A., 1998. Three-dimensional waveform sensitivity kernels, Geophys. J. Int, 132, 521-534.

Marshall, G., Stein, R. \& Tatcher, W., 1991. Faulting geometry and slip from co-seismic elevation changes: the 18 October 1989, Loma Prieta, California, earthquake, Bull. seism. Soc. Am., 81, 1660-1693.

Massonnet, D. \& Feigl, K.L., 1995. Satellite radar interferometric map of the coseismic deformation field of the $\mathrm{M}=6.1$ Eureka Valley, California earthquake of May 17, 1993, Geophys. Res. Lett., 22, 1541-1544.

McQuarrie, N., 2002. Initial plate geometry, shortening variations, and evolution of the Bolivian orocline, Geology, 30, 867-870.

Okada, Y., 1985. Surface deformation due to shear and tensile fault in a half-space, Bull. seism. Soc. Am., 75, 1135-1154.

Okada, Y., Kasahara, K., Hori, S., Obara, K., Sekiguchi, S., Fujiwara, H. \& Yamamoto, A., 2004. Recent progress of seismic observation networks in Japan-Hi-net, F-net, K-NET and KiK-net, Earth Planets Space, 56(8), $15-28$.
Oswald, J. \& Wesnousky, S., 2002. Neotectonics and Quarternary geology of the Hunter Mountain fault zone and Salin Valley region, southeastern California, Geomorphology, 42, 255-578.

Peltzer, G. \& Rosen, P., 1995. Surface displacement of the 17 May 1993 Eureka Valley, California, earthquake observed by SAR Interferometry, Science, 268, 1333-1336.

Powell, M., 1964. An efficient method for finding the minimum of a function of several variables without calculating derivatives, Comput. J., 7, 155162.

Ritsema, J., Deuss, A., van Heijst, H. \& Woodhouse, J.H., 2011. S40RTS: a degree-40 shear-velocity model for the mantle from new Rayleigh wave dispersion, teleseismic traveltime and normal-mode splitting function measurements, Geophys. J. Int, 184(3), 1223-1236.

Roperch, P., Fornari, M., Herail, G. \& Parraguez, G., 2000. Tectonic rotations within the Bolivian Altiplano: implications for the geodynamic evolution of the Central Andes during the late Tertiary, J. geophys. Res., 105, 795820.

Rosen, P.A., Hensley, S. \& Peltzer, G., 2004. Updated repeat orbit interferometry package released, EOS, Trans. Am. geophys. Un., 85, 47.

Rouhollahi, R., Ghayamghamian, M., Yaminfard, F., Suhadole, P. \& Tatar, M., 2012. Source process and slip model of 2005 Dahuiyeh-Zarand earthquake (Iran) using inversion of near-field strong motion data, Geophys. $J$. Int, 189, 669-680.

Sambridge, M., 1999. Geophysical inversion with a neighbourhood algorithm-I. Searching a parameter space, Geophys. J. Int., 138, 479494.

Savage, J., 1987. Effect of crustal layering upon dislocation modeling, J. geophys. Res., 92, 10 595-10 600.

Schaeffer, A. \& Lebedev, S., 2013. Global shear speed structure of the upper mantle and transition zone, Geophys. J. Int., 194, 417-449.

Schmidt, D.A. \& Bürgmann, R., 2006. InSAR constraints on the source parameters of the 2001 Bhuj earthquake, Geophys. Res. Lett., 33, L02315, doi:10.1029/2005GL025109.

Sella, G., Dixon, T. \& Mao, A., 2002. REVEL: a model for recent plate velocities from space geodesy, J. geophys. Res., 107, B42081, doi:10.1029/2000JB000033.

Sudhaus, H. \& Jónsson, S., 2009. Improved source modelling through combined use of InSAR and GPS under consideration of correlated data errors: application to the June 2000 Kleifarvatn earthquake Iceland, Geophys. J. Int., 176, 389-404.

Syracuse, E.M. \& Abers, G.A., 2009. Systematic biases in subduction zone hypocenters, Geophys. Res. Lett., 36, L10303, doi:10.1029/2009GL037487.

Talebian, M. et al., 2004. The 2003 Bam (Iran) earthquake: Rupture of a blind strike-slip fault, Geophys. Res. Lett., 31, L11611, doi:10.1029/2004GL020058.

Talebian, M. et al., 2006. The Dahuiyeh (Zarand) earthquake of 2005 February 22 in central Iran: reactivation of an intramountain reverse fault, Geophys. J. Int., 164, 137-148.

Tsai, V., Hayes, G. \& Duputel, Z., 2011. Constraints on the long-period moment-dip tradeoff for the Tohoku earthquake, Geophys. Res. Lett., 38, L00G17, doi:10.1029/2011GL049129.

USGS, 2010. Available at: http://earthquake.usgs.gov/earthquakes/ eqarchives/year/2003/ (last accessed 27 April 2013).

Vallée, M., Charlety, J., Ferreira, A., Delouis, B. \& Vergoz, J., 2011. SCARDEC: a new technique for the rapid determination of seismic moment magnitude, focal mechanism and source time functions for large earthquakes using body-wave deconvolution, Geophys. J. Int., 184, 338 358.

Vernant, P. et al., 2004. Present-day crustal deformation and plate kinematics in the Middle East constrained by GPS measurements in Iran and northern Oman, Geophys. J. Int., 157, 381-398.

Wald, D. \& Graves, R., 2001. Resolution analysis of finite fault source inversion using one- and three-dimensional Green's functions: 2. Combining seismic and geodetic data, J. geophys. Res., 106, 8767-8788.

Wald, D. \& Heaton, T., 1994. Spatial and temporal distribution of slip for the 1992 Landers, California earthquake, Bull. seism. Soc. Am., 84, 668691. 
Wessel, P. \& Smith, W., 1991. Free software helps map and display data, EOS, Trans. Am. geophys. Un., 72, 441.

Weston, J., Ferreira, A. \& Funning, G.J., 2011. Global compilation of interferometric synthetic aperture radar earthquake source models: 1. Comparisons with seismic catalogs, J. geophys. Res., 116, B08408, doi:10.1029/2010JB008131.

Weston, J., Ferreira, A. \& Funning, G.J., 2012. Systematic comparisons of earthquake source models determined using InSAR and seismic data, Tectonophysics, 532, 61-81.

Wright, T.J., Parsons, B., Jackson, J., Haynes, M.a.F.E., England, P. \& Clarke, P., 1999. Source parameters of the 1 October 1995 Dinar (Turkey) earthquake from SAR interferometry and seismic body wave modelling, Earth. planet. Sci. Lett., 172, 23-37.

Wright, T.J., Lu, Z. \& Wicks, C., 2003. Source model for the Mw 6.7, 23 October 2002, Nenana Mountain Earthquake (Alaska) from InSAR, Geophys. Res. Lett., 30(18), 1974, doi:10.1029/2003GL018014.

\section{SUPPORTING INFORMATION}

Additional Supporting Information may be found in the online version of this article:

Table S1. Summary of measurement periods and perpendicular baselines for the interferograms used in this study where Dsc and Asc refer to descending and ascending tracks, respectively.

Figure S1. Comparison of relative weights used in the joint inversions with the misfits from the separate data set inversions for the three earthquakes: (a) Eureka Valley, (b) Aiquile and (c) Zarand.
Figure S2. (a) Trade-off scatterplots for InSAR only inversion (blue) and joint source inversion (pink) for a synthetic strike-slip faulting event, where the focal mechanism for the input model is shown in black at the top, and the parameters of which are denoted by the green stars. (b) Tradeoff scatterplots for seismic-only and joint inversion results. The format for (a) and (b) follow the same as in Fig. 4.

Figure S3. (a) Trade-off scatterplots for InSAR only inversion (blue) and joint source inversion (pink) for a synthetic thrust faulting event, where the focal mechanism for the input model is shown in black at the top. (b) Tradeoff scatterplots for seismic-only (black) and joint inversion results. The format for (a) and (b) follow the same as in Fig. 4.

Figure S4. Fit of InSAR-only inversion results for the $M_{\mathrm{w}} 6.5$ Zarand earthquake. (a) Ascending interferogram calculated using two images from 2004 September 19 and 2005 March 13, taken on track 285. (b) Descending data calculated using images from 2005 February 17 and 2005 March 24 on track 435. The second row (c) and (d) are synthetic ascending and descending interferograms, respectively, forward modelled using the InSAR-only inversion result. (e)-(f) are the residuals for the ascending and descending data and results, respectively. (http://gji.oxfordjournals.org/lookup/suppl/ doi:10.1093/gji/ggu110/-/DC1).

Please note: Oxford University Press is not responsible for the content or functionality of any supporting materials supplied by the authors. Any queries (other than missing material) should be directed to the corresponding author for the article. 